\title{
Month-to-Month Variability of Winter Temperature over Northeast China Linked to Sea Ice over the Davis Strait-Baffin Bay and the Barents-Kara Sea
}

\author{
HAIXIA DAI \\ Nansen-Zhu International Research Centre, Institute of Atmospheric Physics, Chinese Academy of Sciences, and \\ University of the Chinese Academy of Sciences, Beijing, China \\ KE FAN \\ Nansen-Zhu International Research Centre, Institute of Atmospheric Physics, Chinese Academy of Sciences, and \\ University of the Chinese Academy of Sciences, Beijing, China \\ JIPING LIU \\ Department of Atmospheric and Environmental Sciences, University at Albany, State University of New York, \\ Albany, New York
}

(Manuscript received 24 November 2018, in final form 21 June 2019)

\begin{abstract}
This study focuses on the month-to-month variability of winter temperature anomalies over Northeast China (NECTA), especially the out-of-phase change between December and January-February (colder than normal in December and warmer than normal in January-February, and vice versa), which accounts for $30 \%$ of the past 37 years (1980-2016). Our analysis shows that the variability of sea ice concentration (SIC) in the preceding November over the Davis Strait-Baffin Bay (SIC_DSBB) mainly affects NECTA in December, whereas the SIC over the Barents-Kara Sea (SIC_BKS) significantly impacts NECTA in January-February. A possible reason for the different effects of SIC_DSBB and SIC_BKS on NECTA is that the month-to-month increments (here called DM) of SIC over these two areas between October and November are different. A smaller DM of SIC_ DSBB in November can generate eastward-propagating Rossby waves toward East Asia, whereas a larger DM of SIC_BKS can affect upward-propagating stationary Rossby waves toward the stratosphere in November. Less than normal SIC_DSBB in November corresponds to a negative phase of the sea surface temperature tripole pattern over the North Atlantic, which contributes to a negative phase of the North Atlantic Oscillation (NAO)like geopotential height anomalies via the eddy-feedback mechanism, ultimately favoring cold conditions over Northeast China. However, positive November SIC_BKS anomalies can suppress upward-propagating Rossby waves that originate from the troposphere in November, strengthening the stratospheric polar vortex and leading to a positive phase of an Arctic Oscillation (AO)-like pattern in the stratosphere. Subsequently, these stratospheric anomalies propagate downward, causing the AO-like pattern in the troposphere in JanuaryFebruary, favoring warm conditions in Northeast China, and vice versa.
\end{abstract}

\section{Introduction}

Northeast China (NEC) is an important heavyindustry and agricultural region in China and has been one of the most significant warming regions in not only China but also all of East Asia for at least the last five decades. Understanding of winter air temperature variability over Northeast China has important implications for societal and economic activities. Previous research

Corresponding author: Ke Fan, fanke@mail.iap.ac.cn has focused mainly on the wintertime average climate and associated atmospheric circulation systems, but little attention has been paid to intermonth variations. However, intraseasonal variabilities have a great influence on the climate of China and are significant challenges for climate prediction.

The month-to-month variability of wintertime nearsurface temperature in Northeast China (NECTA) is a prominent feature of climate variability in NEC over the past several decades. Aside from the uniform variations of NECTA in each winter month, there are three types 
of month-to-month variations of temperature over NEC. During the period 1980-2016, the number of years when the monthly temperature anomalies in winter (December, January, and February) present a "negative-positivepositive" or "positive-negative-negative" pattern in Northeast China (colder than normal in December and warmer than normal in January-February, and vice versa, abbreviated as NECTA N++ $_{-}$and NECTA $_{+--}$, respectively) accounts for the largest proportion of the past 37 years (up to $30 \%$ ) among the three types of month-to-month out-of-phase changes (NECTA $_{-++} /$ NECTA $_{+--}$, NECTA $_{+-+}$NECTA $_{-+-}$, NECTA $_{++-} /$ NECTA $_{--+}$).

Early works revealed that the East Asian winter monsoon (EAWM) is the most critical system affecting winter climate over Northeast China (Ding et al. 2014; Hu et al. 2015; Zhuang et al. 2018). A strong winter monsoon, characterized by a strong Siberian high (Ding and Krishnamurti 1987), a broad and deepened East Asian trough (Wang and He 2012), an enhanced East Asian subtropical jet stream, and a weakened polar front jet stream (Yang et al. 2002; Li and Yang 2010) in the upper troposphere facilitates frequent outbreaks of cold air, such as cold waves, leading to cold and snowy winters in Northeast China. Statistical analyses of the EAWM from 2013 to 2018 indicate that subseasonal variations of the EAWM are responsible for the intraseasonal variations of winter temperature in China, and the intraseasonal variations of the EAWM might be influenced by geopotential height anomalies related to stratospheric processes (Wang et al. 2013), blocking high activities over the North Pacific (Si et al. 2014), El NiñoSouthern Oscillation (ENSO) events (Wang et al. 2015), the Arctic Oscillation (AO) (Si et al. 2016), the polar vortex of the Northern Hemisphere, and anomalous sea surface temperature (SST) over the Atlantic (Zhang and Song 2018). These findings correspond to other research in which large-scale atmospheric circulation patterns have been found to affect the strength of the EAWM and the winter temperature of Northeast China (Wu and Wang 2002; Liu et al. 2010; Wang and Chen 2010; Chen et al. 2013; He et al. 2017). Moreover, the phase transition of the North Atlantic Oscillation (NAO)/AO accompanied by a super ENSO event (Geng et al. 2017) has also been found to be related to a phase reversal of the Siberian high and EAWM in boreal winter, which may further affect cold blocking events and local cooling over East Asia (Chang and Lu 2012).

Anomalous Arctic sea ice is an important factor that has considerable influence on the EAWM and has been considered as a predictor of winter temperature over Northeast China (Dai et al. 2018). A close relationship between autumn Arctic sea ice anomalies and Eurasian climate variability has been demonstrated (Inoue et al. 2012; Outten and Esau 2012; Yang and Wu 2013; Sato et al. 2014; Chen et al. 2014; Gao et al. 2015; Semenov and Latif 2015). Fan et al. (2018) illustrated that winter sea ice cover in the Barents Sea can affect the frequency of spring dust weather over North China via the snow cover over western Siberia. Honda et al. (2009) and $\mathrm{Wu}$ and Zhang (2010) both showed that wintertime $\mathrm{AO} / \mathrm{NAO}$ is significantly correlated with anomalous Arctic sea ice, which may further have an influence on Eurasian winter. Liu et al. (2012) also documented that the change in atmospheric circulation linked to reduced autumn sea ice shows much broader meridional meander at midlatitudes. This circulation change results in more frequent episodes of blocking patterns that lead to increased cold surges over large parts of northern continents. A strengthened Siberian high and East Asian trough (Wu et al. 2011; Zuo et al. 2016), together with increased cold surges, all favor cold conditions in Northeast China. However, such studies have focused mainly on the seasonal time scale, paying little attention to the intraseasonal impact of Arctic sea ice on monthly surface climate variability during wintertime. The relationship between preceding Arctic sea ice and intermonth variations of winter temperature over Northeast China remains unclear.

Therefore, the purpose of this study focuses on the linkage of preceding Arctic sea ice with intraseasonal reversal events in winter temperature over Northeast China (i.e., NECTA N++ $_{-+}$NECTA $_{+--}$events). It also expected to improve the skill of month-to-month variability prediction of winter temperature over Northeast China.

The remainder of the paper is structured as follows. The data used are described in section 2 . The month-tomonth variability of temperature anomalies in Northeast China and Arctic sea ice is examined in section 3. Possible mechanisms by which Arctic sea ice affects NECTA are introduced in section 4. Section 5 provides an overall summary and offers some further discussion.

\section{Data and methods}

The observed monthly surface temperature from 160 weather stations in China administered by the China Meteorological Administration is employed in this study. Monthly atmospheric reanalysis data developed by the National Centers for Environment Prediction and $\mathrm{Na}-$ tional Center for Atmospheric Research (Kalnay et al. 1996), with a horizontal resolution of $2.5^{\circ} \times 2.5^{\circ}$, are also used. The variables used include sea level pressure (SLP), zonal and meridional wind at 200 and $850 \mathrm{hPa}$ (UV200 and UV850), air temperature, and geopotential height at all 
levels. The monthly averaged sea ice concentration (SIC) and SST are from the Met Office Hadley Centre, with a $1^{\circ} \times 1^{\circ}$ latitude-longitude spatial resolution (Rayner et al. 2003).

This study focuses on the month-to-month variability of winter temperature over Northeast China, which covers the area of $42^{\circ}-52^{\circ} \mathrm{N}$ and $120^{\circ}-135^{\circ} \mathrm{E}$. The data span the period of 1980-2016. Each winter is defined as December of the prior year and January-February of the current year. When the NECTA in each winter month (December, January, February) presents a "negativepositive-positive" pattern (NECTA N-+ $_{-}$, colder than normal in December and warmer than normal in January-February) or "positive-negative-negative" pattern $\left(\mathrm{NECTA}_{+--}\right)$, we record it as an event and define NECTA $_{-++}$as the positive phase of this event. The vertical and zonal components of Plumb (1985)'s wave activity fluxes are calculated to diagnose the stratosphere-troposphere interaction patterns associated with NECTA N++ $_{-+}$events:

$$
\begin{aligned}
& F_{x}=\frac{p}{2 a^{2} \cos \phi}\left[\left(\frac{\partial \psi^{\prime}}{\partial \lambda}\right)^{2}-\psi^{\prime} \frac{\partial^{2} \psi^{\prime}}{\partial \lambda^{2}}\right] \\
& F_{z}=\frac{2 p \Omega^{2} \sin ^{2} \phi}{N^{2} a}\left(\frac{\partial \psi^{\prime}}{\partial \lambda} \frac{\partial \psi^{\prime}}{\partial z}-\psi^{\prime} \frac{\partial^{2} \psi^{\prime}}{\partial \lambda \partial z}\right)
\end{aligned}
$$

where $p$ is pressure $/ 1000 \mathrm{hPa}, a$ is the mean radius of Earth, $\Omega$ is the angular velocity of rotation, $N$ is the buoyancy frequency, $\psi^{\prime}$ is the perturbation geostrophic streamfunction, $\lambda$ and $\phi$ are longitude and latitude, respectively, and primes indicate the departure from the zonal mean; $z=-H \ln p$, where $H$ is a constant scale height ( $H=8000$ in this paper). The vertical component of the wave activity flux is proportional to the meridional heat flux. It can be used not only to describe poleward heat flux but also to represent upwelling tropospheric wave energy into the lower stratosphere (Eliassen and Palm 1961). Here we calculate the vertical wave activity flux averaged between $50^{\circ}-70^{\circ} \mathrm{N}$ since the zonal belt $40^{\circ}-80^{\circ} \mathrm{N}$ is the region where the highest variance in November meridional heat flux at $100 \mathrm{hPa}$ occurs, especially between $50^{\circ}-70^{\circ} \mathrm{N}$ (not shown).

The horizontal component of flux generalized by Takaya and Nakamura (2001) is also used, to diagnose the stationary wave propagation in the troposphere:

$$
\begin{aligned}
W_{x}= & \frac{p}{2 a^{2}|\mathbf{U}|}\left\{\frac{U}{\cos \phi}\left[\left(\frac{\partial \psi^{\prime}}{\partial \lambda}\right)^{2}-\psi^{\prime} \frac{\partial^{2} \psi^{\prime}}{\partial \lambda^{2}}\right]\right. \\
& \left.+V\left(\frac{\partial \psi^{\prime}}{\partial \lambda} \frac{\partial \psi^{\prime}}{\partial \phi}-\psi^{\prime} \frac{\partial^{2} \psi^{\prime}}{\partial \lambda \partial \phi}\right)\right\},
\end{aligned}
$$

$$
\begin{aligned}
W_{y}= & \frac{p}{2 a^{2}|\mathbf{U}|}\left\{U\left(\frac{\partial \psi^{\prime}}{\partial \lambda} \frac{\partial \psi^{\prime}}{\partial \phi}-\psi^{\prime} \frac{\partial^{2} \psi^{\prime}}{\partial \lambda \partial \phi}\right)\right. \\
& \left.+V \cos \phi\left[\left(\frac{\partial \psi^{\prime}}{\partial \phi}\right)^{2}-\psi^{\prime} \frac{\partial^{2} \psi^{\prime}}{\partial \phi^{2}}\right]\right\}
\end{aligned}
$$

where $\mathbf{U}=(U, V, 0)^{\mathrm{T}}$ denotes a steady zonally inhomogeneous basic flow.

Additionally, given that the interannual variability of sea ice is small, we use the month-to-month increments of sea ice cover to represent its variation deviations, which could force greater response of general atmospheric or oceanic circulations compared with the anomaly relative to climatology. Month-to-month increments used in this paper are defined as the differences between the current month and previous month (hereafter referred to as DM), which is similar to the "year-to-year increment" method proposed by Fan et al. (2008). In this study, all data and indices are detrended before the analysis (e.g., SIC, SST, SLP, and temperature).

\section{Month-to-month variability of NECTA and Arctic sea ice}

\section{a. Features of NECTA and Arctic sea ice}

The month-by-month NECTA in each winter (December, January, and February) spanning 1980-2016 is shown in Fig. 1a. The number of years in which NECTA reverses on the subseasonal time scale (both black and green marks in Fig. 1a) reaches 21, including 11 years of NECTA ${ }_{-++}$NECTA $_{+--}$events (green marks in Fig. 1a). In light of the large number of such phenomena (60\% during the $37-y r$ period) and the significance over the entire region (Figs. 1b-d), this study focuses on this phenomenon and aims to reveal its possible causes.

Composite differences of SIC in preceding autumn between five strong NECTA +++ years $(1992,1995,2002$, 2003, and 2015) and six strong NECTA +-- years (1980, 1984, 1987, 2000, 2014, and 2016) are examined for the period 1980-2016. The most significant SIC anomalies occur in November (Fig. 2a). Davis Strait-Baffin Bay is ice-free in September and October (Figs. 3a,b). Thus, when Northeast China is colder than normal in December and warmer in January-February, lighter than normal SIC occurs in November over Davis Strait-Baffin Bay. Meanwhile, in September and October, slighter and thinner SIC related to winter NECTA ${ }_{-++} / \mathrm{NECTA}_{+-}$is scattered in a tiny portion of the Barents-Kara Sea. The climatology of SIC indicates the southward sustained extension starts in October over the Barents-Kara Sea and in November over the Davis Strait-Baffin Bay respectively (Fig. 3) and the variations peak in November in 
(a) 1980-2016, NEC, Temp anomalies

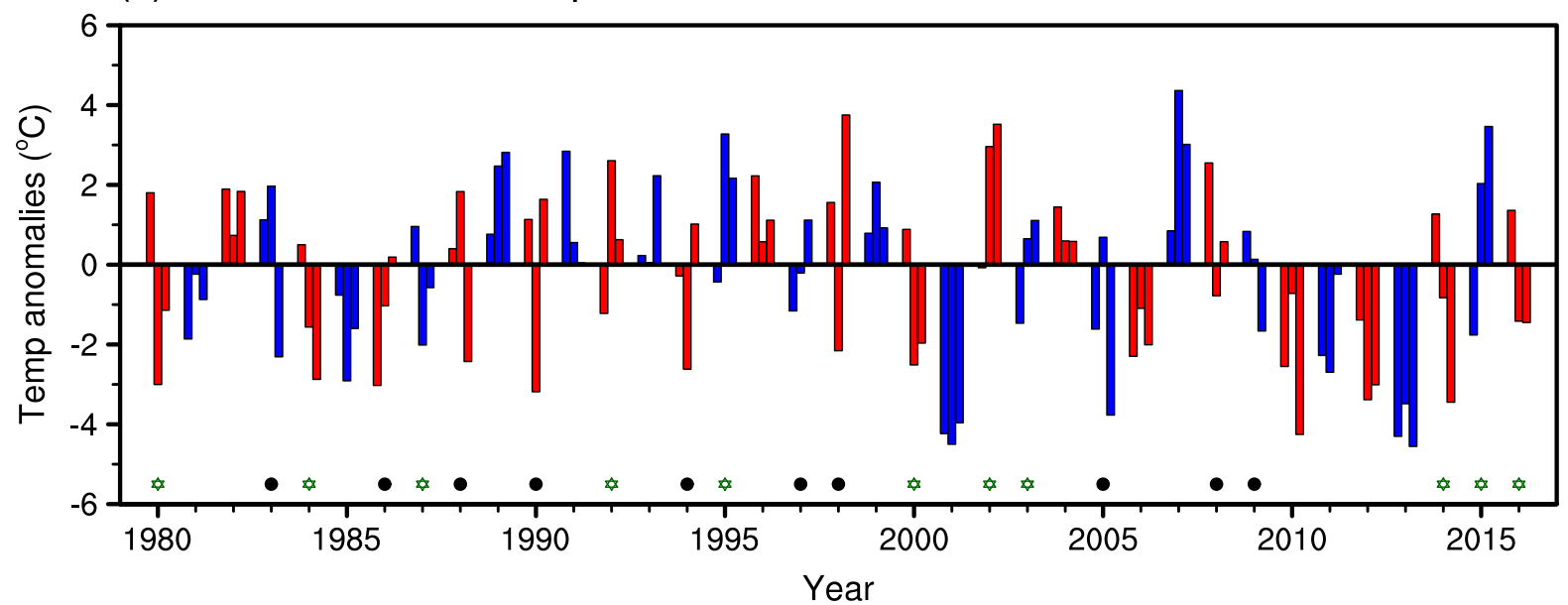

(b) Dec

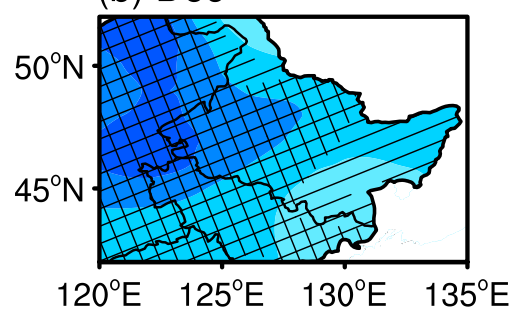

(c) Jan

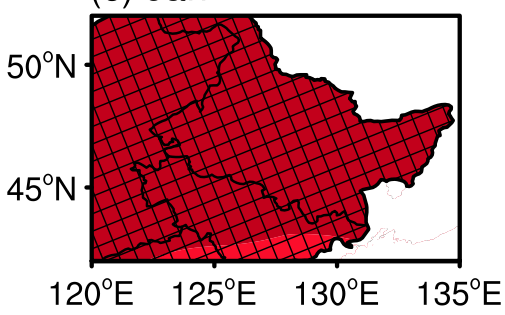

(d) Feb

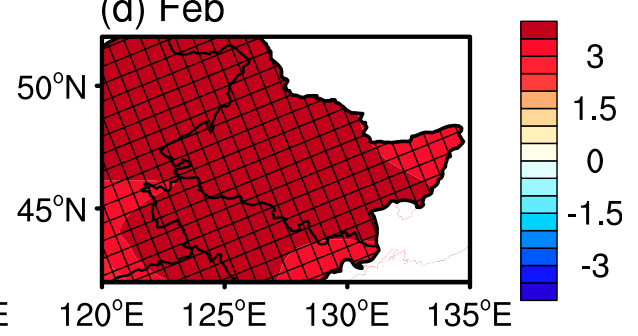

FIG. 1. (a) Time series of temperature anomalies over Northeast China $\left({ }^{\circ} \mathrm{C}\right)$ in each winter month during 1980-2016. Composite spatial patterns of temperature between $\mathrm{NECT}_{-++}$and NECTA ${ }_{+--}$for (b) December, (c) January, and (d) February $\left({ }^{\circ} \mathrm{C}\right)$. Years with NECTA ${ }_{-++} /$ NECTA $_{+--}$events are marked by green dots in (a), and years of other subseasonal reversal types of NECTA are marked by black dots. Crosshatched (hatched) regions in (b)-(d) are statistically significant at the 95\% (90\%) confidence level, based on the Student's $t$ test.

both domains. This means that SIC anomalies over the Barents-Kara Sea and the Davis Strait-Baffin Bay in the preceding November might be related to NECTA -++1 NECTA $+--_{+}$events.

Next we respectively define the area-averaged November SIC during 1979-2015 over Davis Strait-Baffin Bay (SIC_DSBB; $62^{\circ}-75^{\circ} \mathrm{N}, 58^{\circ}-65^{\circ} \mathrm{W}$ ) and the BarentsKara Sea (SIC_BKS; $75^{\circ}-83^{\circ} \mathrm{N}, 0^{\circ}-80^{\circ} \mathrm{E}$ ) as SIC indices to construct composites of atmospheric and oceanic states. The correlation coefficient between detrended indices of SIC_DSBB and SIC_BKS is only -0.05 , which is far smaller than the statistically significant value at $90 \%$ confidence level (0.27). That means that SIC values over these two domains affect NECTA independently. The eight heaviest years $(1983,1986,1990,1993,1999,2008$, 2011, and 2015) and six lightest years (1980, 1984, 2002, 2006, 2010, and 2012) of SIC_DSBB are chosen to compute composite differences (exceeding one standard deviation). The five heaviest years $(1988,1994,1997,2002$, and 2014) and five lightest years $(1979,1984,2009,2012$, and 2015) of SIC_BKS are also selected. Composite differences of NECTA based on SIC_DSBB (low minus high) and SIC_BKS (high minus low) in each winter month are shown in Figs. $2 \mathrm{~b}$ and $2 \mathrm{c}$. Only the composite of NECTA in December achieves the $90 \%$ confidence level, despite the "negative-positive-positive" trend of NECTA in Fig. 2b. This indicates that SIC anomalies over the Davis Strait-Baffin Bay may have an influence on NECTA $_{-++} /$NECTA $_{+--}$events, but only significantly affect the temperature in December over Northeast China. For SIC_BKS, heavier than normal SIC over the Barents-Kara Sea does favor a warmer winter in Northeast China, especially in January-February. Thus, NECTA $_{-++}\left(\right.$NECTA $\left._{+--}\right)$events may be attributable to lighter (heavier) than normal SIC_DSBB and heavier (lighter) than normal SIC_BKS in the preceding November; also, anomalous SIC_DSBB mainly affects NECTA in December, whereas anomalous SIC_BKS shows distinct impacts on NECTA in January-February.

\section{b. Atmospheric circulations related to NECTA $A_{-++} / N E C T A_{+--}$}

The leading mode of monthly NECTA, as identified by the empirical orthogonal function (EOF) analysis, accounts for about $80 \%$ of the total variance, showing a monopole structure. Thus, we carry out further analyses 


\section{(a) Autumn SIC, Comp Diff based on NECTA ${ }_{+++} /$NECTA $_{+--}$}

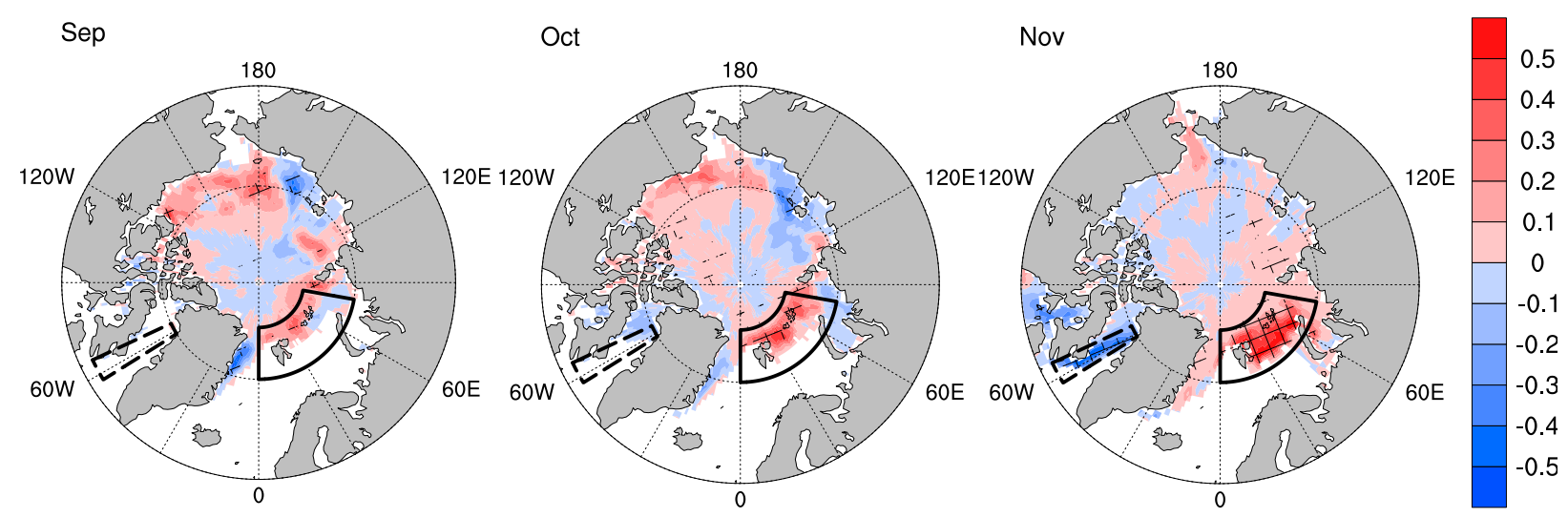

(b) NEC Temp, Comp Diff based on SIC_DSBB
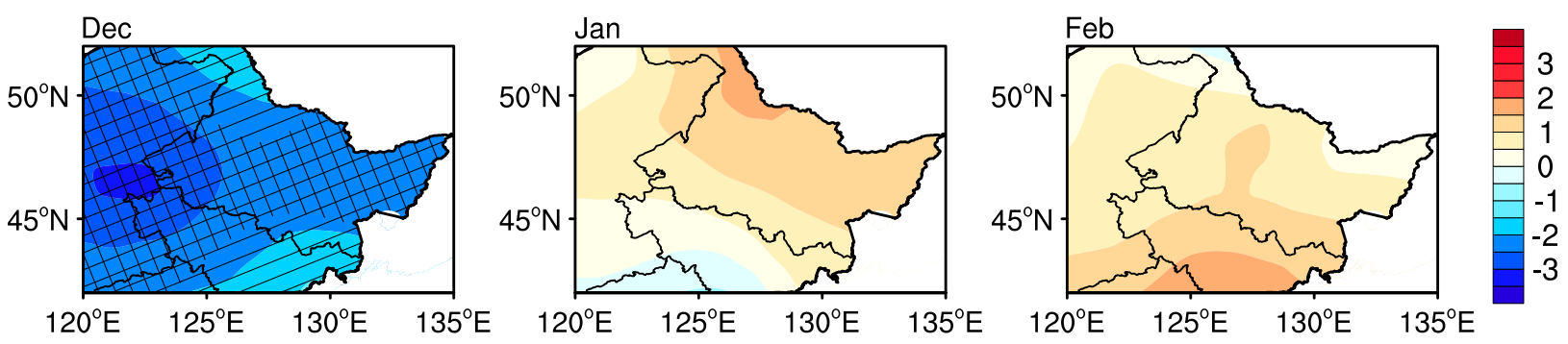

(c) NEC Temp, Comp Diff based on Nov SIC_BKS
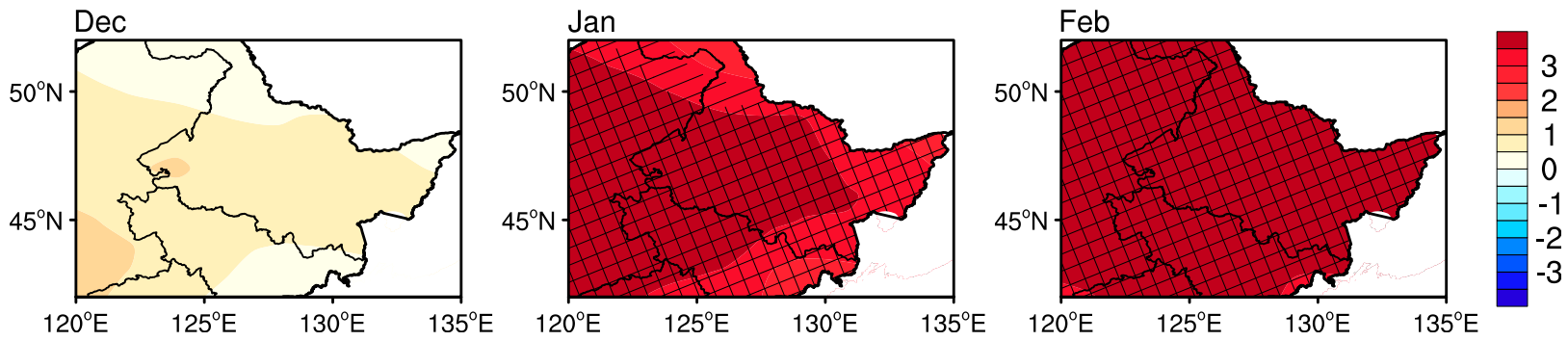

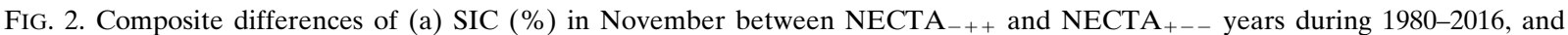
December, January, and February temperature anomalies $\left({ }^{\circ} \mathrm{C}\right)$ over Northeast China based on the SIC over the (b) Davis Strait-Baffin Bay (low minus high) and (c) Barents-Kara Sea (high minus low) in November during 1979-2015. Statistically significant values at the 95\% (90\%) confidence level (Student's $t$ test) are crosshatched (hatched).

based on the original patterns of NECTA. As the preceding November SIC_DSBB and SIC_BKS mainly have an influence on NECTA in December and January-February respectively, composites of variables related to $\mathrm{NECTA}_{-++} / \mathrm{NECTA}_{+--}$events are calculated, including SLP, UV200, geopotential height at $100 \mathrm{hPa}$ (H100), and zonal cross sections and horizontal components of wave activity flux, to investigate the possible physical processes through which SIC_DSBB and SIC_BKS in November affect NECTA.

The composite differences of SLP, UV200, and H100 in each winter month between NECTA $_{-++}$and
NECTA $_{+--}$years are shown in Fig. 4 . When the NECTA of each winter month is characterized as "negativepositive-positive" a stronger than normal Siberian high and Aleutian low dominate the mid-to-high latitudes of the Northern Hemisphere in December. The negative phase of an NAO-like pattern also exists. These conditions all favor strong cold-air activities invading Northeast China. Later, in January-February, the general circulation systems are in accordance with warmer than normal temperature over Northeast China. The Siberian high decays markedly in January, and both the Siberian high and Aleutian low turn to be much weaker in February 
(a) Sep

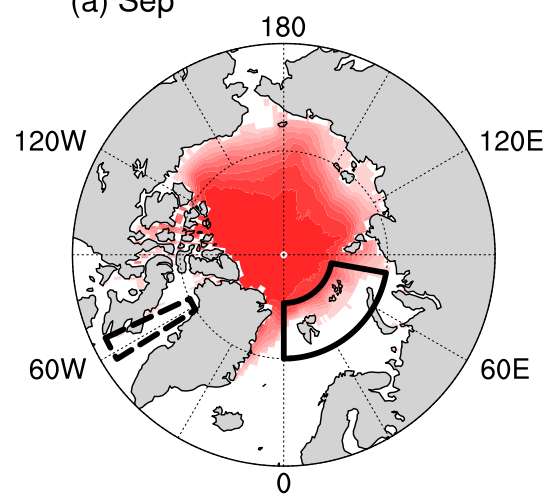

(d) Dec

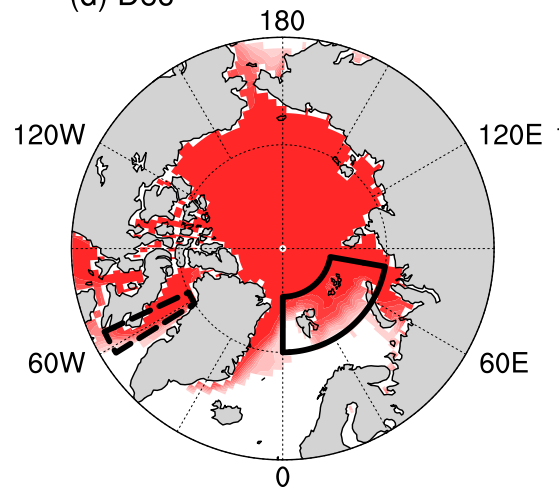

(b) Oct

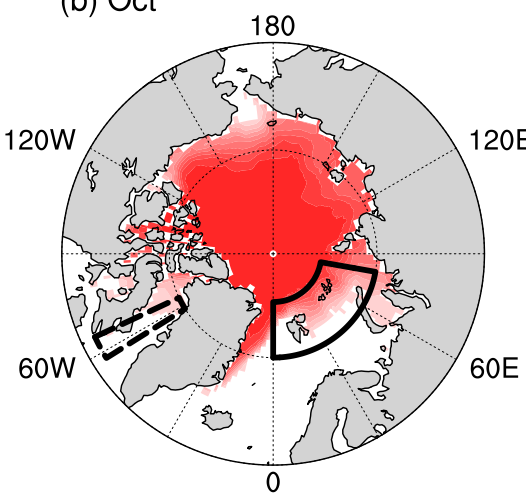

(e) Jan

(c) Nov

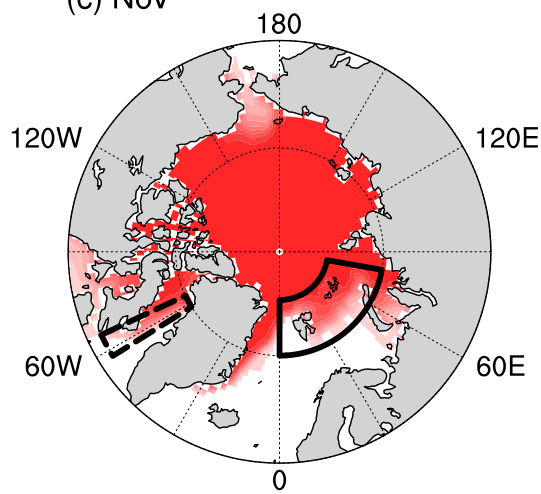

(f) Feb
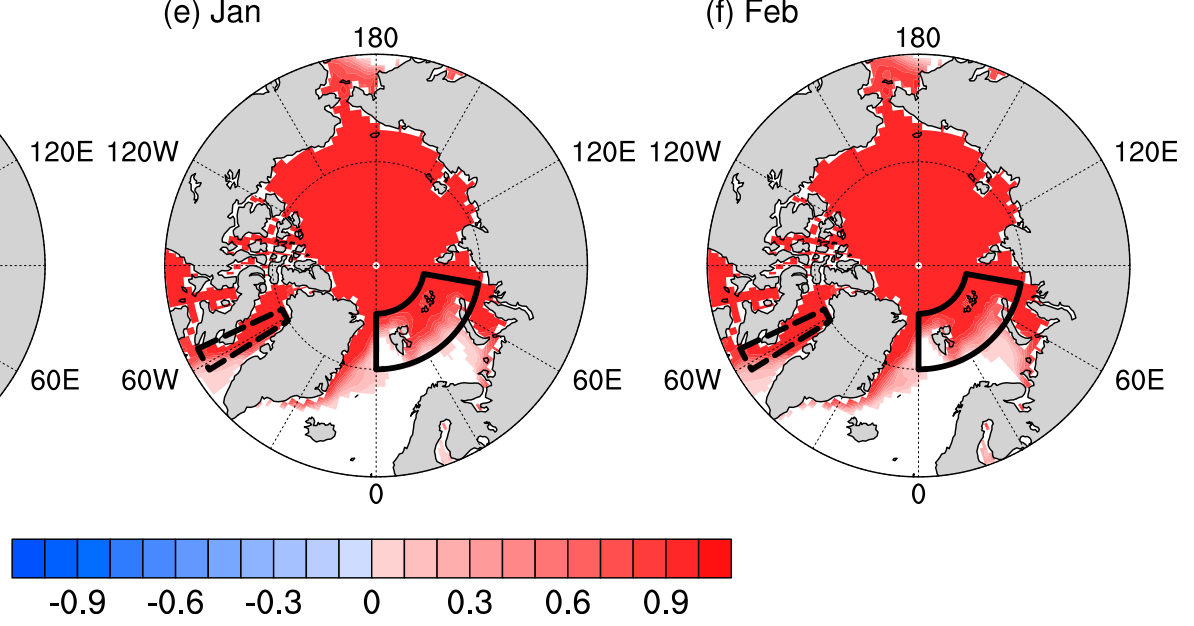

FIG. 3. Spatial patterns of climatology of SIC (\%) in (a) September, (b) October, (c) November, (d) December, (e) January, and (f) February during 1981-2010.

(Figs. 4a-c). Correspondingly, a weaker than normal polar front jet stream and a stronger than normal East Asian subtropical jet stream appear at $200 \mathrm{hPa}$ in December, and the phase converts in January-February (Figs. 4d-f). The same is true with the East Asian trough (not shown). In the Arctic stratosphere, the polar vortex weakens in December and then develops from January (Figs. 4g-i).

The atmospheric circulations related to $\mathrm{NECTA}_{-++} /$ NECTA $_{+--}$shown in Fig. 4 indicate that when NECTA reverses from December to January-February, the Siberian high, Aleutian low, and polar front jet all exhibit intermonth reversal between December and January. Furthermore, the anomalous signals in the Arctic stratosphere may be responsible for the out-of-phase relationship of NECTA between December and January-February.

c. Atmospheric circulations related to sea ice over the Davis Strait-Baffin Bay and the Barents-Kara Sea

\section{1) Sea ice over Davis Strait-BAfFin Bay}

Several studies have demonstrated that sea ice over the Davis Strait-Baffin Bay is related to large-scale atmospheric circulations, like the NAO/AO and Southern Oscillation (Wang et al. 1994; Mysak et al. 1996; Park et al. 2015; Stern and Heide-Jørgensen 2016). The variations of SIC over the Davis Strait-Baffin Bay have a substantial influence on Greenland blocking (Chen and Luo 2017) and are linked to autumn surface air temperatures around coastal Greenland via 500-hPa blocking patterns (Ballinger et al. 2018). Moreover, it is also an important factor for summer rainfall over Eurasia (Wang and Guo 2004; Wu et al. 2013).

As mentioned in section 3a, lighter than normal SIC over the Davis Strait-Baffin Bay in November mainly affects the temperature in December over Northeast China. Influenced by lighter than normal SIC_DSBB, a strengthened Siberian high (Fig. 5a) together with a strengthened East Asian trough (not shown) and significantly weakened the polar front jet stream (Fig. 5d) favor a southward invasion of cold air masses from the Arctic. Moreover, the geopotential anomalies in December are similar to those of a negative phase of the NAO. These atmospheric circulation patterns all favor a colder condition of Northeast China in December. However, the Siberian high and Aleutian low 
(a) Dec, SLP Comp Diff

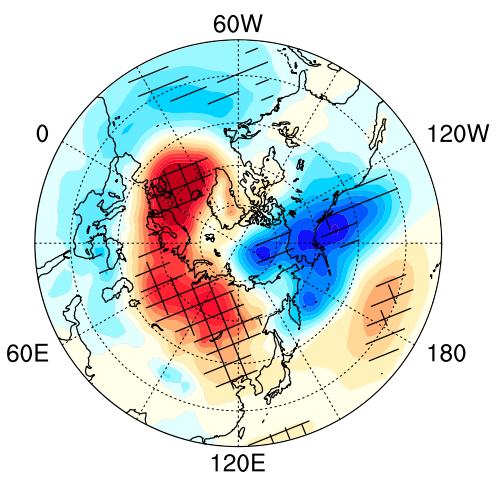

(d) Dec, UV200 Comp Diff

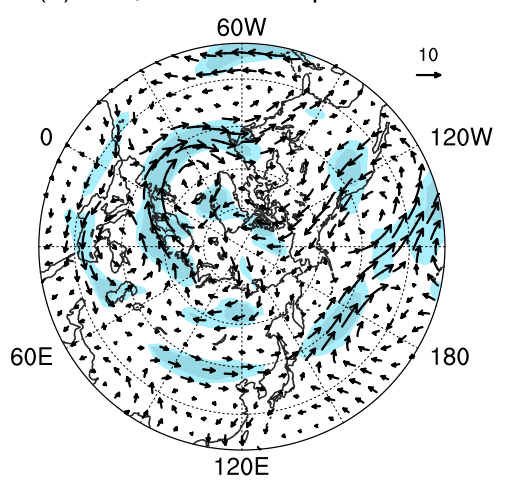

(g) Dec, H100 Comp Diff

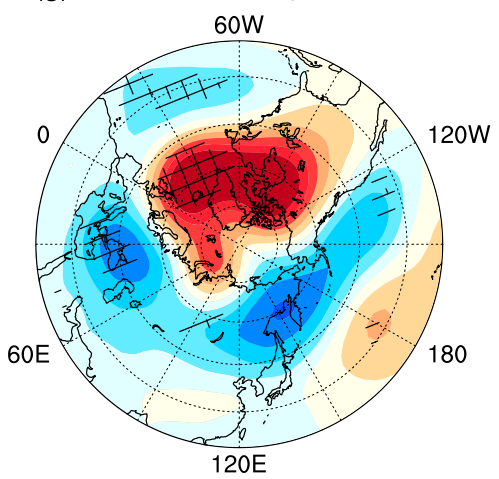

(b) Jan, SLP Comp Diff

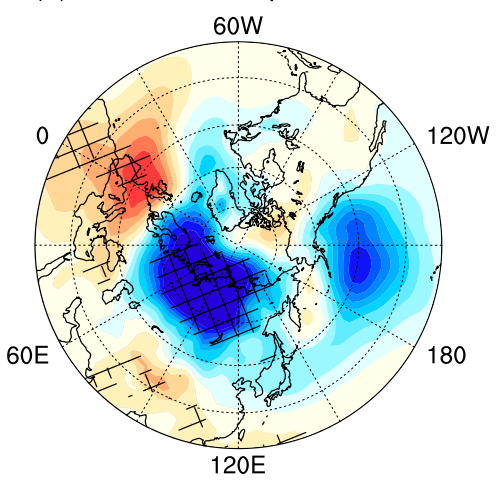

(e) Jan, UV200 Comp Diff

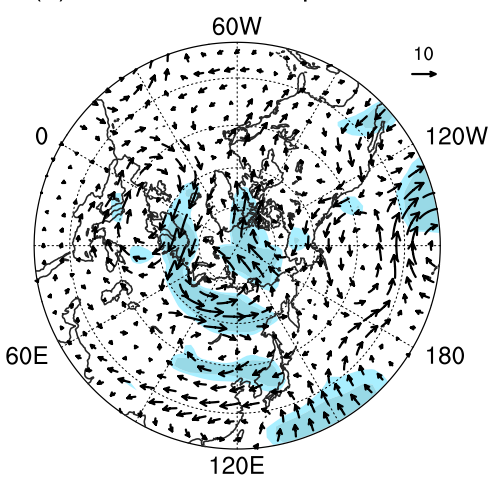

(h) Jan, H100 Comp Diff

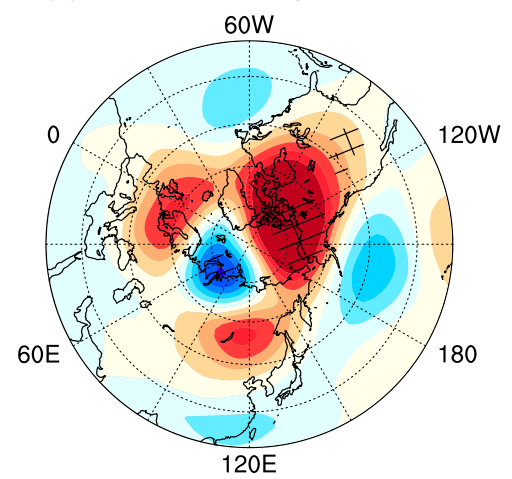

(c) Feb, SLP Comp Diff

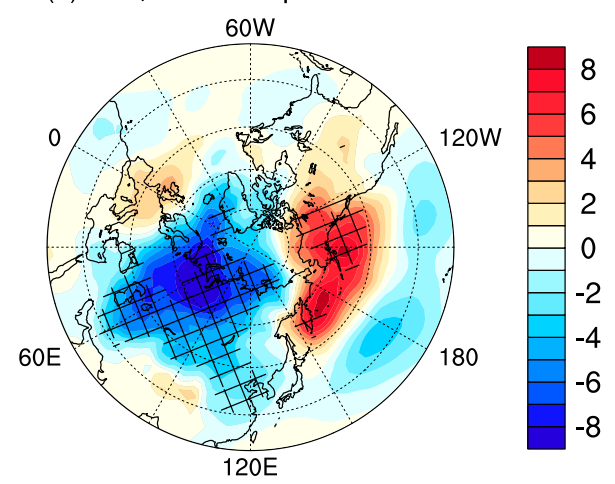

(f) Feb, UV200 Comp Diff

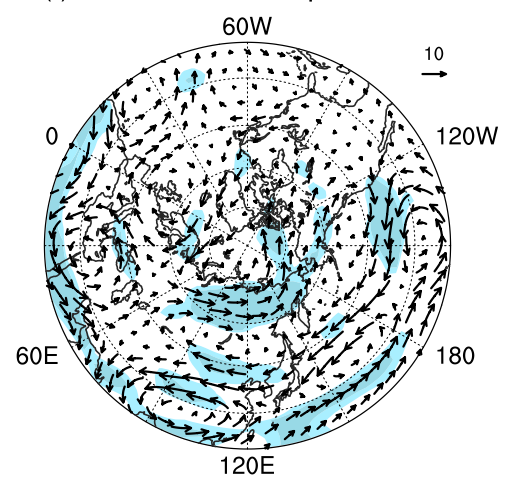

(i) Feb, H100 Comp Diff

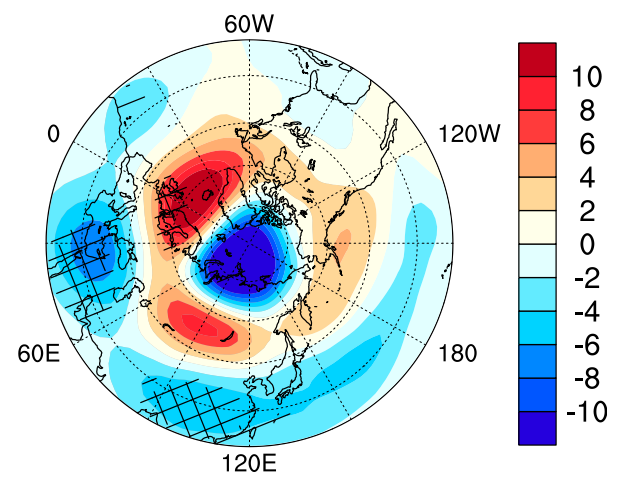

FIG. 4. Composite differences of (a)-(c) sea level pressure (hPa), (d)-(f) 200-hPa wind ( $\mathrm{m} \mathrm{s}^{-1}$ ), and (g)-(i) 100-hPa geopotential height

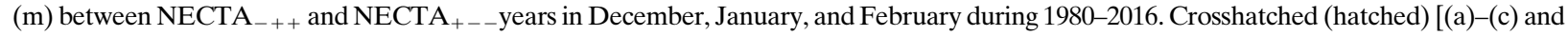
(g)-(i)] and dark (light) shading [(d)-(f)] regions are statistically significant at the $95 \%(90 \%)$ confidence level, based on the Student's $t$ test.

become weak in January and February respectively (Figs. 5b,c). Also, in the upper troposphere, the polar front jet shows a strengthened trend in January and February (Figs. 5e,f). Nonetheless, these atmospheric anomalies in January-February are not strong enough to significantly affect the temperature in Northeast China.

\section{2) SeA ICE over the BARents-Kara SeA}

The Barents-Kara Sea is always the key domain for climate variations in Eurasia. The relationships between
SIC_BKS and the EAWM or surface temperature have been demonstrated in many studies (Wu et al. 1999; Petoukhov and Semenov 2010; Sun et al. 2016). Such work has illustrated that a decline in SIC_BKS might amplify the Siberian high, with a stationary Rossby wave generated thermally through anomalous turbulent heat fluxes. The weakened upper-level zonal wind produced in response to this reduced SIC_BKS will also act as a favorable condition for the invasion of cold air to northern East Asia. 
(a) Dec, SLP Comp Diff

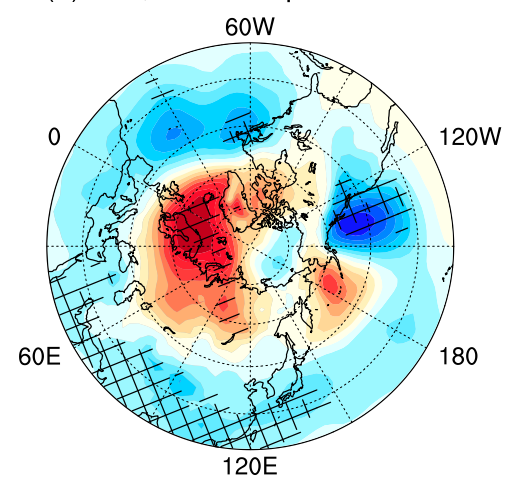

(d) Dec, UV200 Comp Diff

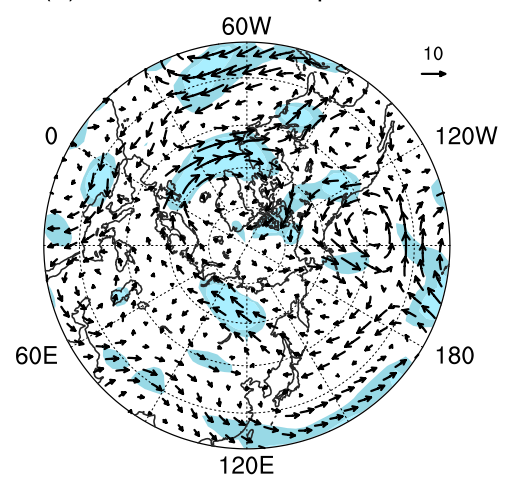

(g) Dec, H100 Comp Diff

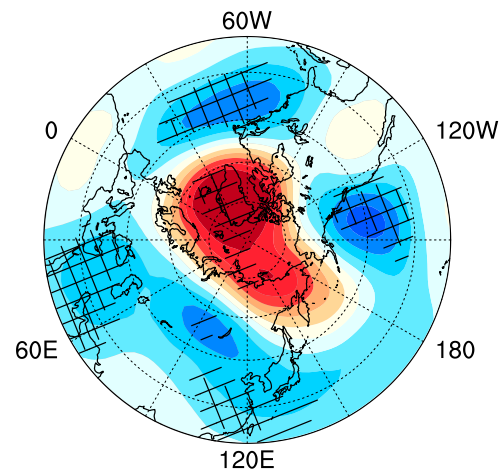

(b) Jan, SLP Comp Diff

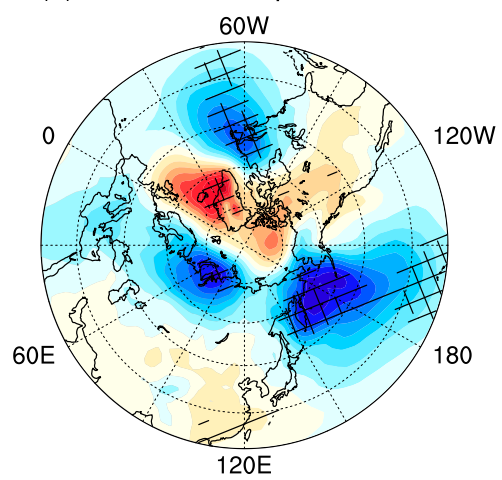

(e) Jan, UV200 Comp Diff

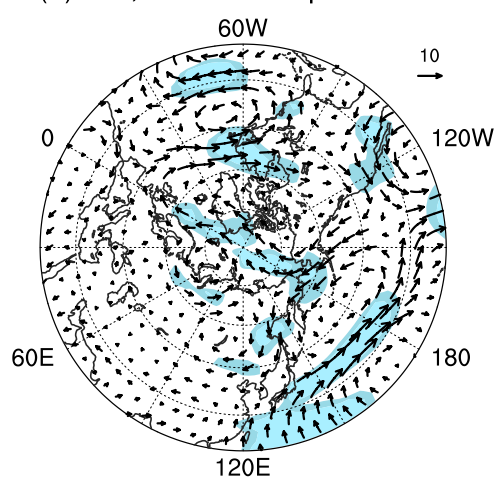

(h) Jan, H100 Comp Diff

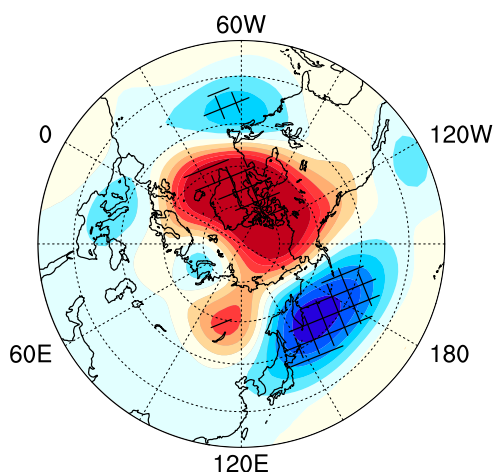

(c) Feb, SLP Comp Diff

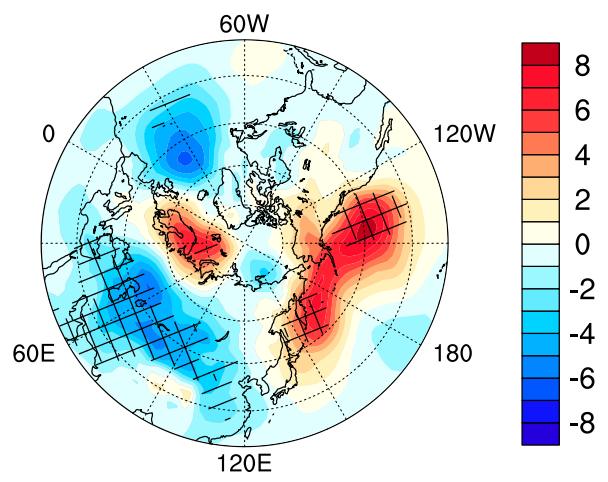

(f) Feb, UV200 Comp Diff

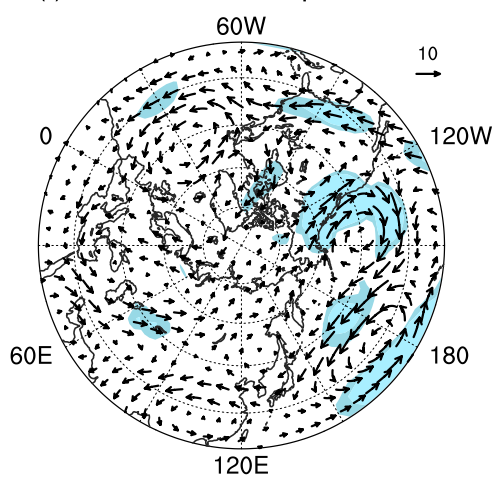

(i) Feb, H100 Comp Diff

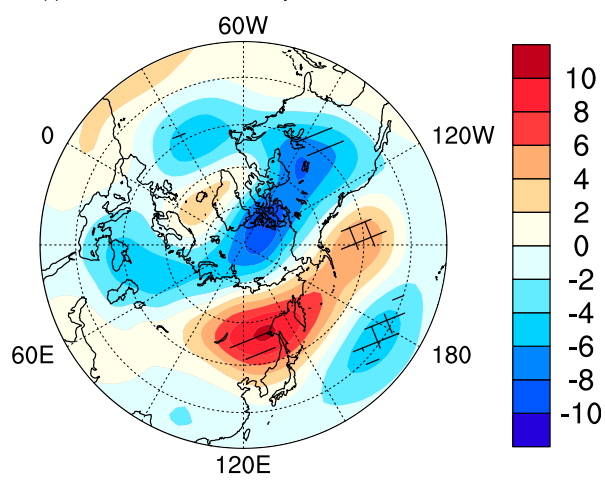

FIG. 5. As in Fig. 4, but the composite differences are calculated between light and heavy SIC in November over the Davis Strait and Baffin Bay during 1979-2015.

Analyses show that the Siberian high and Aleutian low both weaken in January-February, corresponding to the increased SIC_BKS in November, and the spatial pattern of SLP features a structure that resembles the positive phase of the AO (Figs. 6b,c). In the upper troposphere, a strengthened polar front jet stream prevents a southward invasion of cold air masses from the Arctic (Figs. 6e,f), and the southeasterlies of an anticyclone over Northeast Asia in February transport warm and wet flow from the Northwest Pacific to Northeast China, which is conducive to a warm condition there. Moreover, the polar vortex at
$100 \mathrm{hPa}$ evidently strengthens and a positive phase of an AO-like pattern appears in both January and February in the stratosphere (Figs. 6h,i). However, no significant signals of critical atmospheric circulations (like the Siberian high, Aleutian low, East Asian subtropical jet stream, and polar front jet) exist in the troposphere and stratosphere in December (Figs. 6a,d,g).

These results are consistent with the analyses in sections $3 \mathrm{a}$ and $3 \mathrm{~b}$. When SIC_DSBB reduces in November, Northeast China is colder in December, along with a stronger Siberian high and Aleutian low in the 
(a) Dec, SLP Comp Diff

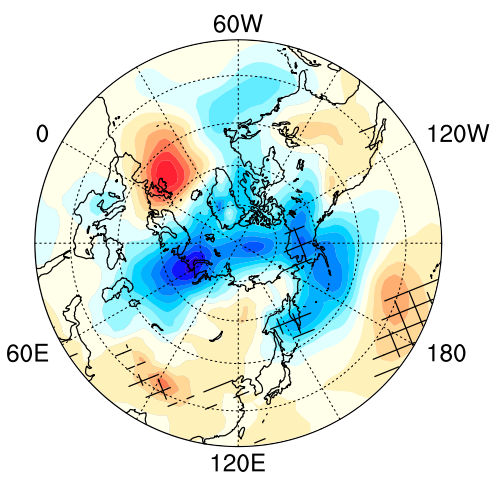

(d) Dec, UV200 Comp Diff

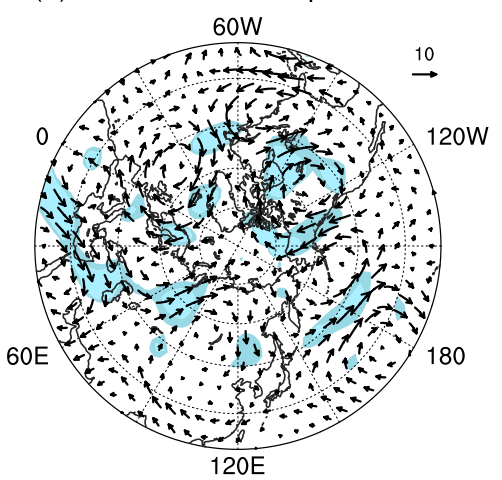

(g) Dec, H100 Comp Diff

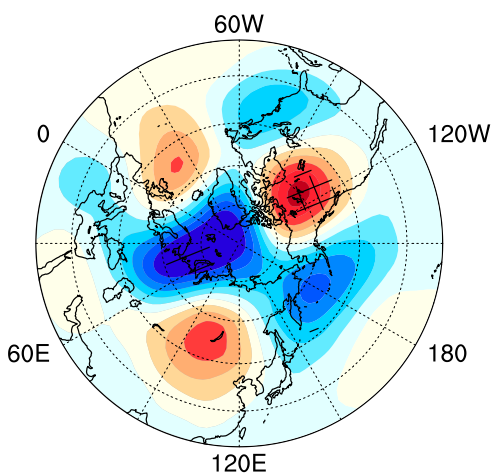

(b) Jan, SLP Comp Diff

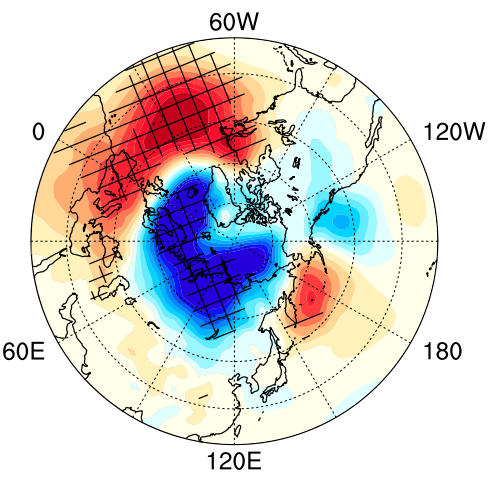

(e) Jan, UV200 Comp Diff

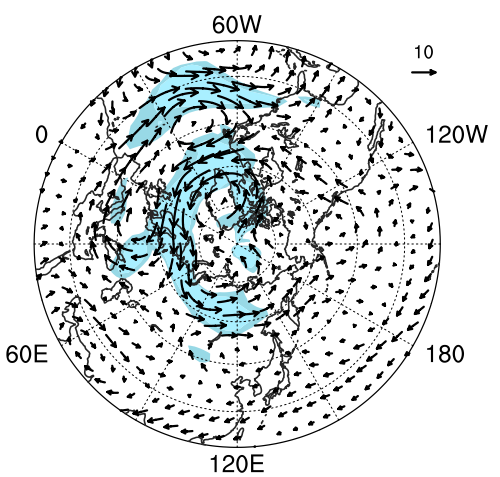

(h) Jan, H100 Comp Diff

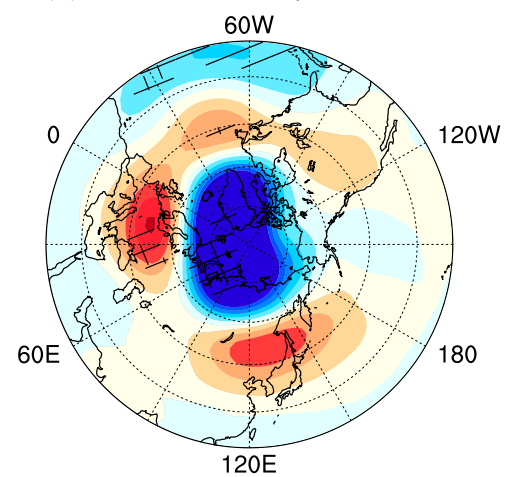

(c) Feb, SLP Comp Diff

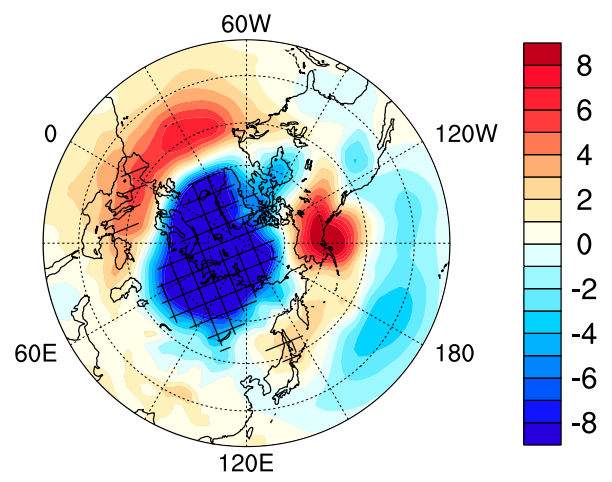

(f) Feb, UV200 Comp Diff

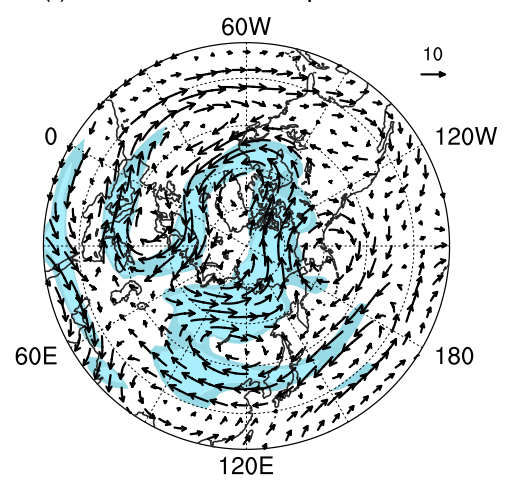

(i) Feb, H100 Comp Diff

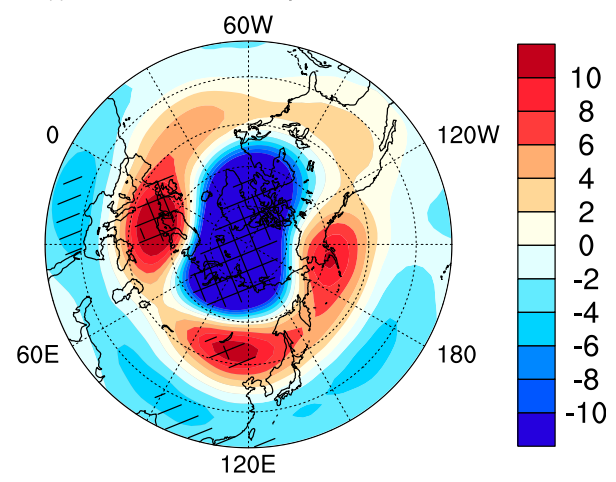

FIG. 6. As in Fig. 4, but the composite differences are calculated between heavy and light SIC in November over the Barents-Kara Sea during 1979-2015.

lower troposphere, and a weakened polar front jet in the upper troposphere. However, if SIC_BKS is anomalously heavy in November at the same time, the atmospheric circulations turn to be conducive to a warm condition over Northeast China in January-February. The atmospheric circulation heterogeneity related to NECTA $_{-++} /$NECTA $_{+--}$events and anomalous SIC DSBB and SIC_BKS is the geopotential pattern in the Arctic stratosphere. The strength and the evolution of the polar vortex differ from each other based on the above three circumstances. Thus, we may infer that the out-of-phase change in temperature anomalies between December and January-February is related to stratospheric circulation anomalies, which may themselves be attributable to SIC_DSBB and SIC_BKS anomalies.

\section{The mechanism behind the differing contributions of SIC over the Davis Strait-Baffin Bay and the Barents-Kara Sea}

A zonal cross section and the horizontal components of wave activity flux are calculated to diagnose the 


\section{WAF Comp Diff (NECTA ${ }_{-++}-$NECTA $_{+--)}$}

(a) Nov

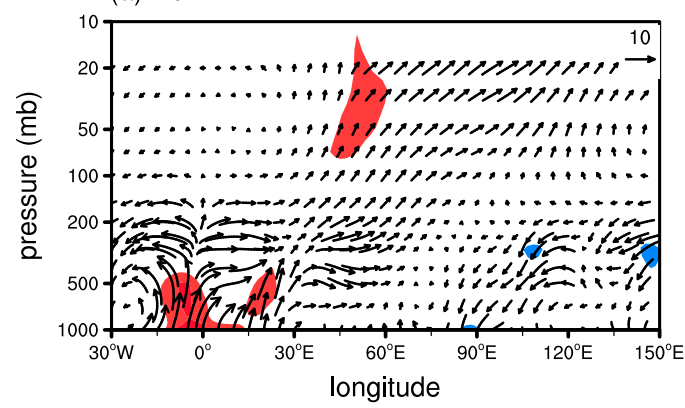

(c) Jan

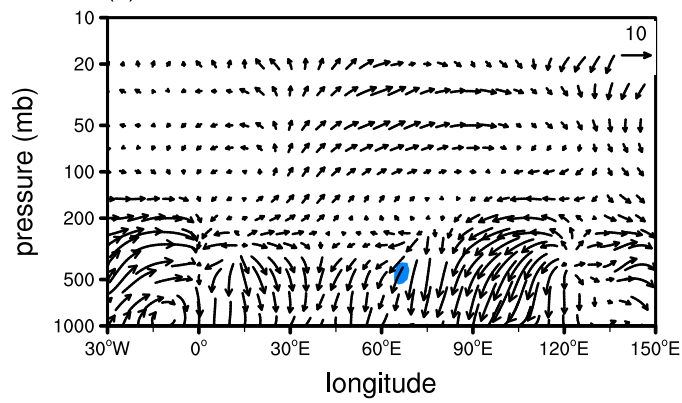

(b) Dec

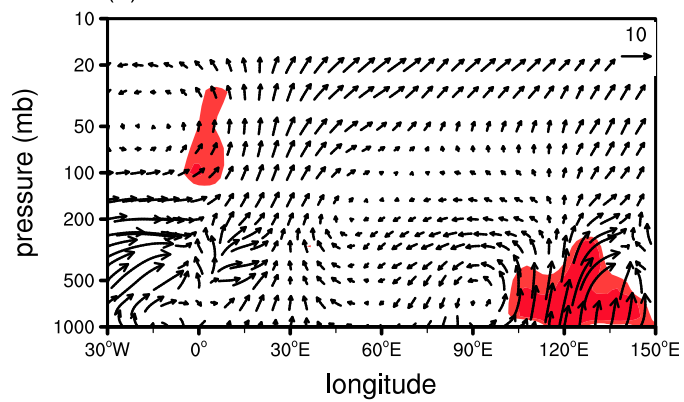

(d) Feb

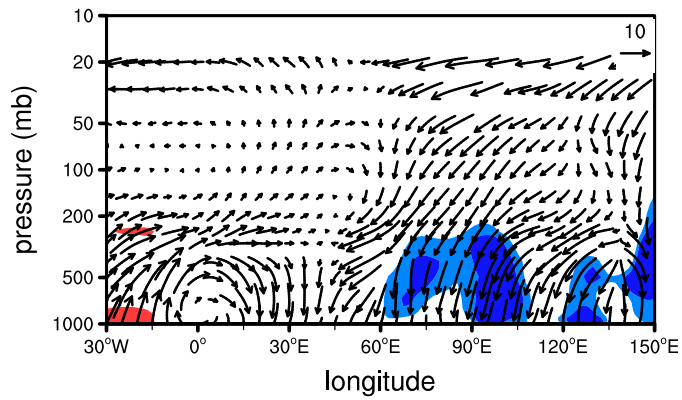

FIG. 7. Composite differences of zonal and vertical Plumb's (1985) wave activity flux at $60^{\circ} \mathrm{N}$, averaged between $50^{\circ}$ and $70^{\circ} \mathrm{N}$ (arrows; $\mathrm{m}^{2} \mathrm{~s}^{-2}$ ) between NECTA -++ and NECTA +-- years in (a) November, (b) December, (c) January, and (d) February. Statistically significant values of vertical wave activity flux at the $95 \%(90 \%)$ confidence level (Student's $t$ test) have dark (light) shading.

patterns of stratosphere-troposphere interaction and stationary wave propagation in the troposphere during NECTA $_{-++} /$NECTA $_{+--}$events and the anomalous circumstances of SIC DSBB and SIC BKS to explore the possible mechanisms related to $\mathrm{NECTA}_{-++} /$ NECTA $_{+--}$events.

Figure 7 shows a longitude-pressure cross section at $60^{\circ} \mathrm{N}$ (averaged over all latitudes between $50^{\circ}$ and $70^{\circ} \mathrm{N}$ ) of the mean wave activity flux difference between NECTA $_{-++}$and NECTA +-- years. In November, anomalous upward propagation is initiated around the prime meridian and spreads over to the Eastern Hemisphere (Fig. 7a), and this eastward transmission then abates in December (Fig. 7b). In January, remnant upward flux is still seen at upper levels around $0^{\circ} \mathrm{E}$, but the major flux over Eurasia is downward (Fig. 7c). This downward flux is enhanced both in the troposphere and stratosphere till February (Fig. 7d). The propagation of anomalies related to NECTA $_{-++} /$NECTA $_{+--}$events corresponds to stratospheric circulations characterized by a weaker polar vortex in December and a stronger one from January (Figs. 4g-i). Eliassen-Palm flux is also considered (not shown in this paper), which illustrates that an upward and slightly poleward flux appears in the midlatitudes along the polar waveguide (Dickinson 1968) in the troposphere and in the stratosphere in November. The upward flux is enhanced in the following month, and becomes weak in the stratosphere and downward in the troposphere in January. Then, stronger downward flux appears in both the troposphere and stratosphere in February.

Thus, we hypothesize that anomalous SIC in the preceding November may affect the upward Rossby waves originating from the troposphere in November and December, affecting the stratospheric polar vortex. Later, in January-February, with the onset of strong stratospheric-tropospheric coupling, zonal mean geopotential height, and wind anomalies propagate down from the stratosphere into the troposphere all the way to the surface (Kuroda and Kodera 1999). Resultant tropospheric height anomalies in January-February are consistent with opposite phases of the dominant mode of variability in December, leading to the out-of-phase change in NECTA between December and JanuaryFebruary. To examine this hypothesis, we diagnose the wave activity flux with the anomalous SIC in the 
WAF Comp Diff

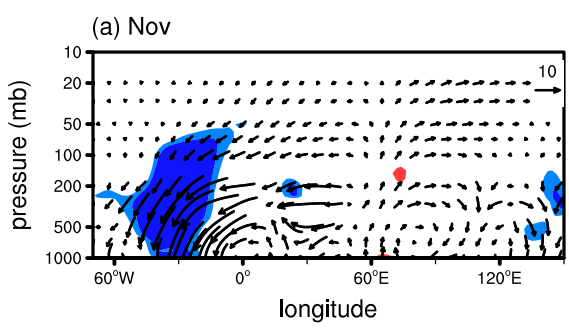

(b) Dec

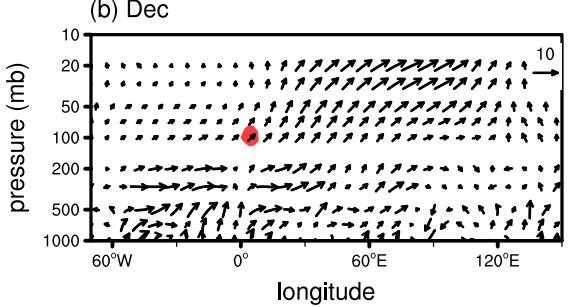

(c) Jan

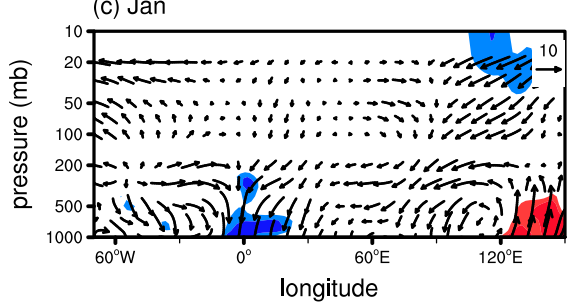

(d) Feb

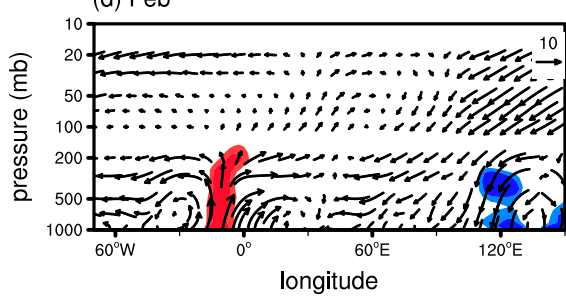

WAF\&H500 Comp Diff
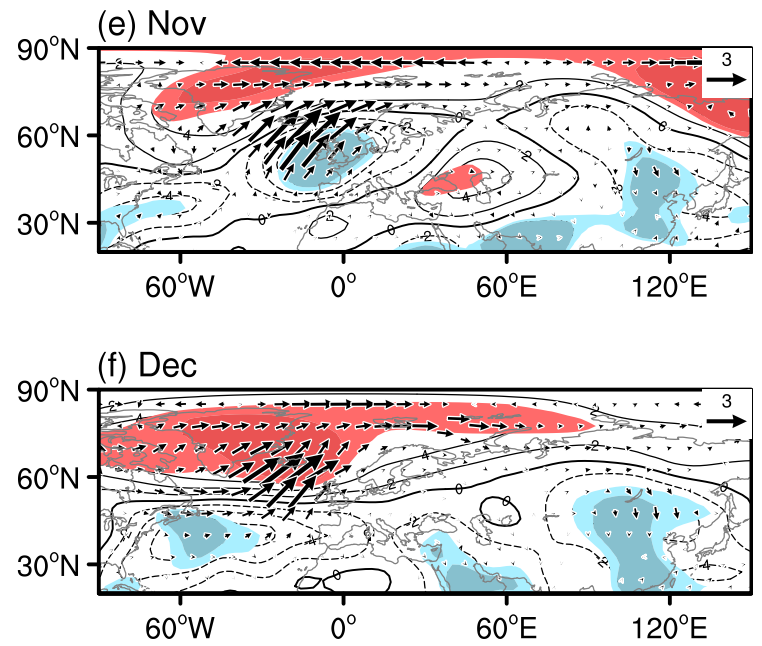

(g) Jan

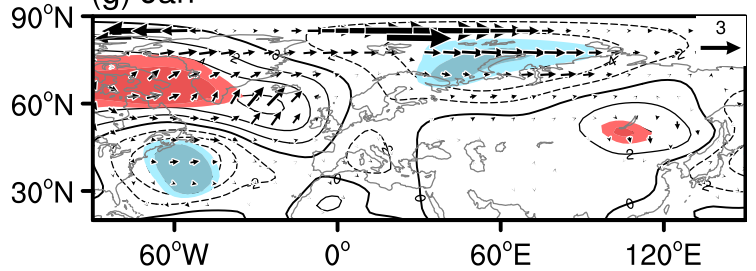

(h) Feb

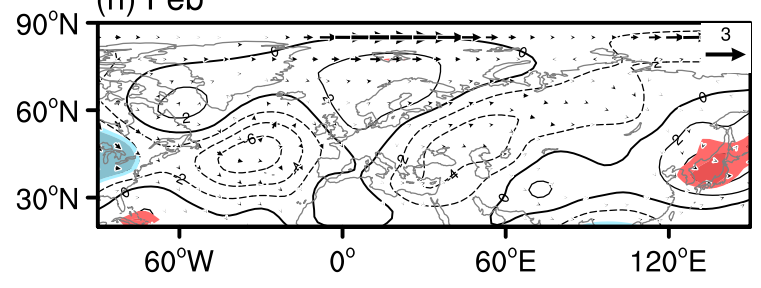

FIG. 8. Composite differences of (a)-(d) zonal and vertical Plumb's (1985) wave activity flux at $60^{\circ} \mathrm{N}$, averaged between $50^{\circ}$ and $70^{\circ} \mathrm{N}$ (arrows; $\mathrm{m}^{2} \mathrm{~s}^{-2}$ ); (e)-(h) 500-hPa geopotential height (contours; interval $=2 \mathrm{~m}$ ) and horizontal Takaya and Nakamura's (2001) wave activity flux (arrows; $\mathrm{m}^{2} \mathrm{~s}^{-2}$ ) from November to February between light and heavy SIC in November over Davis Strait-Baffin Bay during 1979-2015. Statistically significant values of vertical wave activity flux at the 95\% (90\%) confidence level (Student's $t$ test) have dark (light) shading.

Davis Strait-Baffin Bay and the Barents-Kara Sea, respectively.

\section{a. Mechanism of SIC over Davis Strait-Baffin Bay}

A composite vertical section of wave activity flux based on anomalous SIC_DSBB is presented in the left column of Fig. 8, demonstrating that reduced SIC DSBB in November is unable to excite the upward wave trains into the stratosphere in November (Fig. 8a). In December, slight vertical waves propagate into the stratosphere around the prime meridian, and then downward fluxes appear in eastern Asia from January (Figs. 8b-d). However, those vertical fluxes are too weak to have any significant influence on NECTA (below the 90\% confidence level) in January-February. Horizontally, wave trains from the North Atlantic spread east over eastern Asia and deepen the East Asian trough in November and December (right-hand column of Fig. 8). But the eastward wave trains disappear in the following January-February. This means that anomalous SIC DSBB only generates eastward-propagating Rossby waves toward East Asia in November and December.

SST anomalies regressed on SIC_DSBB index values are shown in Figs. 9a and 9b, revealing the existence of a tripole pattern (negative pattern) in the North Atlantic corresponding to lighter than normal SIC_DSBB from 


\section{Sea Surface Temperature .Reg. on SIC_DSBB}

(a) Nov

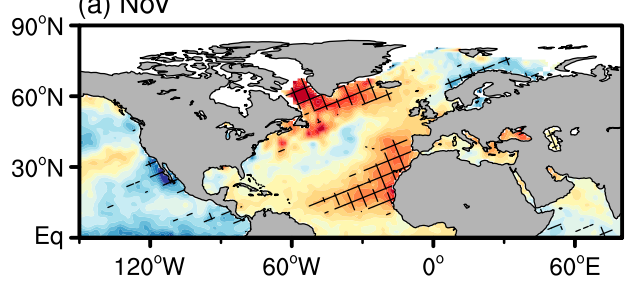

(b) Dec

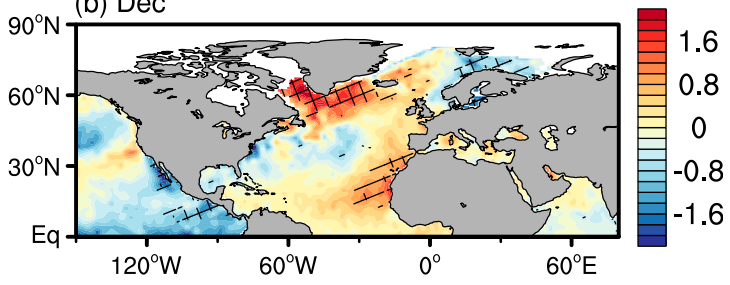

Surface Heat Flux .Reg. on SIC_DSBB

(c) Nov

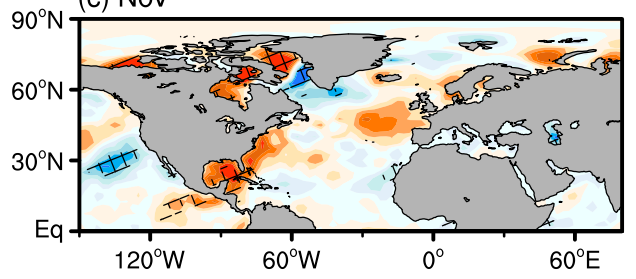

(d) Dec

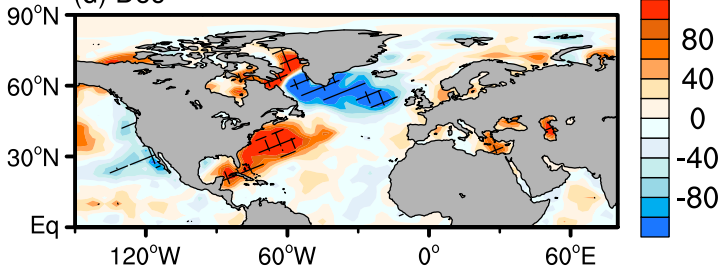

UV850 .Reg. on SIC_DSBB
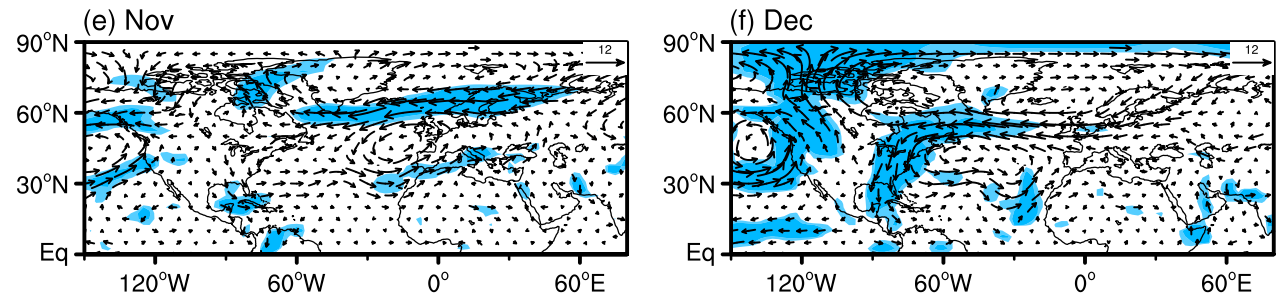

HGT \& SF500 .Reg. on SIC_DSBB
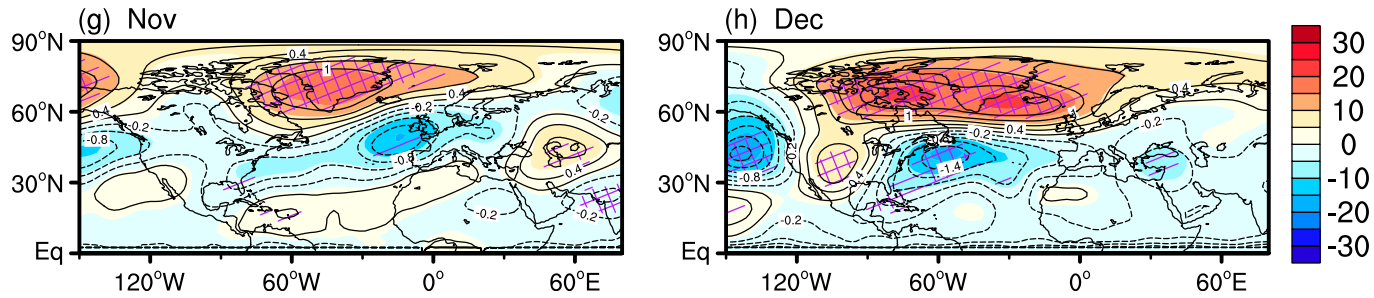

FIG. 9. Anomalous (a),(b) sea surface temperature (shading; ${ }^{\circ} \mathrm{C}$ ), (c),(d) surface heat flux (shading; $\mathrm{W} \mathrm{m}^{-2}$; positive values denote upward heat flux), (e),(f) $850-\mathrm{hPa}$ wind (vector; $\mathrm{m} \mathrm{s}^{-1}$ ), and (g),(h) 500-hPa geopotential height (shading; $\mathrm{m}$ ) and streamfunction (contour; $10^{6} \mathrm{~m}^{2} \mathrm{~s}^{-2}$ ) in November and December regressed onto November SIC index over Davis Strait-Baffin Bay $(\times-1.0)$ during 1979-2015. Statistically significant values at the 95\% (90\%) confidence level (Student's $t$ test) are crosshatched (hatched) in (a)-(d), (g), and (h) and have dark (light) shading in (e) and (f).

November to December. An extratropical SST anomaly can induce two interacting anomalous forcings: diabatic heating and eddy vorticity forcing (Peng and Whitaker 1999). Peng et al. (2003) summarized that the response of atmospheric general circulation to the North Atlantic SST tripole is characterized by an NAO-like dipole over the Atlantic, which is primarily maintained by the eddyfeedback mechanism. The SST tripole pattern in the North Atlantic initially induces anomalous heating, which drives a heating-forced anomalous flow; the latter interacts with the storm tracks, resulting in anomalous eddy vorticity forcing; and this eddy forcing drives an eddy-forced NAO-like anomalous flow, which in turn influences the heating.

Thus, we can apply the above eddy-feedback mechanism to explain the role of the SST anomalies in the anomalous SIC_DSBB forcing. The lighter SIC_DSBB in November corresponds to warmer local SST, which 
further induces the colder SST center along $30^{\circ} \mathrm{N}$ and warmer SST center east of $30^{\circ} \mathrm{W}$ along $15^{\circ} \mathrm{N}$ via local airsea interactions in November and December (Figs. 9a,b). The SST tripole pattern drives anomalous heating tripole over North Atlantic in November, characterizing as a negative heating center at $60^{\circ} \mathrm{N}$ and positive heating centers around $40^{\circ}$ and $70^{\circ} \mathrm{N}$. The heating tripole persists to December and keeps developing (Figs. 9c,d). The SSTinduced heating leads to a couple of south-north oriented cyclone-anticyclone pairs (Figs. 9e,f) in the lower troposphere. Correspondingly, the streamfunction tendency due to eddy vorticity forcing features a dipole over North Atlantic and contributes to a negative phase of NAO-like geopotential height anomalies at $500 \mathrm{hPa}$ (Figs. 9g,h). Under this circulation, westerlies blowing from North Atlantic to Europe are weakened (Fig. 5d), which further enhances broader meanders that are likely to firm blocking patterns (Liu et al. 2012) and ultimately favor cold weather conditions over Northeast China in December. However, the atmospheric circulation anomalies mentioned above cannot persist to January and February (figures not shown), which illustrates that the SIC_DSBBinduced horizontal wave trains cannot affect Northeast China in January and February (Figs. 8g,h).

\section{b. Mechanism of SIC over the Barents-Kara Sea}

Several early studies demonstrated that the variability of SIC_BKS in November, rather than other earlier months, is mostly associated with an NAO-like pattern through the stratosphere pathway (García-Serrano et al. 2015; King et al. 2016; García-Serrano et al. 2017). SIC_BKS anomalies thermally generate a stationary Rossby wave across Eurasia through anomalous turbulent heat fluxes, which tend to induce circulation anomalies not only in surface but also in the upper level in Eurasia (Honda et al. 2009; Kim et al. 2014). The constructive interferences of this anomalous wavelike structure with the climatological wave pattern would lead to amplified meridional heat fluxes and, thus, enhanced injection of tropospheric wave activity into the stratosphere, thereby affecting the polar vortex (Nakamura et al. 2015; Sun et al. 2015; Nakamura et al. 2016). These anomalies then propagate downward and impact transient-eddy activity in the upper troposphere, helping to settle and maintain the NAO-like pattern near the surface (Baldwin and Dunkerton 2001). This stratospheric mechanism has been identified in observational data and AGCM sensitivity experiments.

In conjunction with anomalously heavy SIC_BKS in November, the regional turbulent heat fluxes decrease and less heat release into the atmosphere (Fig. 10a), causing the "cold Arctic and warm continent" pattern of surface air temperature (SAT) anomalies (Fig. 10b). The local positive and negative centers of SLP shown in
Fig. 10c largely collocate with the SAT anomalies. Large-scale circulation anomalies within the midtroposphere exhibit a wavelike pattern from the BKS to eastern Eurasia; that is, a positive anomaly develops over BKS, a negative anomaly forms over the Central Siberian Plateau and a downstream positive anomaly appears over Lake Baikal (Fig. 10d). The anomalies above resemble the pattern found by Honda et al. (2009) and Kim et al. (2014). Geopotential height anomalies in the Eurasian sector have been identified as a source of vertical propagation of planetary waves (Plumb 1985; Kuroda and Kodera 1999). Thus, the regressions of the zonal cross section of wave activity fluxes along $60^{\circ} \mathrm{N}$ onto November SIC_BKS indices are calculated during the wintertime (Fig. 10e).

Consistent with previous works, upward wave propagation is suppressed over Eurasia as a result of enhanced sea ice over the Barents-Kara Sea in November. During early winter, the suppression becomes distinct in both the troposphere and stratosphere. The stratospheric geopotential height anomalies are consistent with a strengthened polar vortex during wintertime, and a positive phase of the AO-like pattern appears in January-February (Figs. 6g-i). Later in January and February, the response pattern of zonal-mean zonal wind to enhanced SIC_BKS in November is characterized by a statistically significant meridional dipole in middle latitudes, with enhanced westerlies in the latitude band $50^{\circ}-70^{\circ} \mathrm{N}$ in both troposphere and stratosphere and reduced westerlies in the band $30^{\circ}-40^{\circ} \mathrm{N}$ in troposphere (not shown). This structure projects well onto the positive phase of $\mathrm{AO}$ and indicates the downward propagation of AO-like pattern from the stratosphere to the troposphere.

Consequently, stratosphere-troposphere interaction plays an important role in SIC_BKS impacting winter temperature in Northeast China. Increased November SIC_BKS sustains to December, inducing negative anomalies of local turbulent heat flux (Fig. 10a) and further generating a Rossby wave train-like anomaly crossing Eurasia (Fig. 10d). This tropospheric wave train affects vertical wave activity, modulating the stratospheric polar vortex strength in November and December and exciting a positive phase of the AO-like pattern in the stratosphere. Later, in January-February, the AO-like pattern propagates downward and favors a warmer than normal condition in Northeast China.

\section{c. Why does the sea ice over the Davis Strait-Baffin Bay and the Barents-Kara Sea have different influences on NECTA?}

In this section, we examine why SIC_DSBB has a significant impact on NECTA in December whereas 
(a) Nov, THF Reg. on SIC_BKS

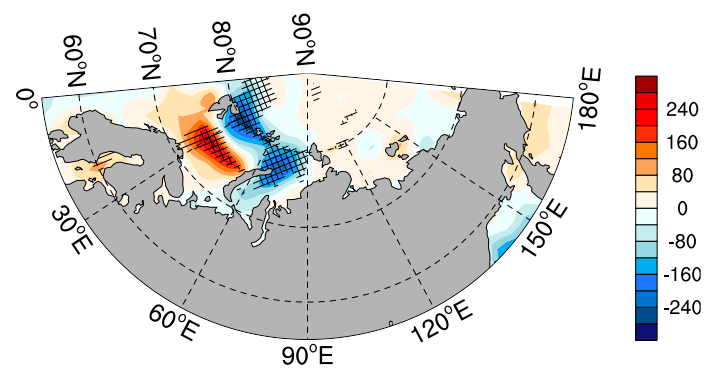

(b) Nov, SAT Reg. on SIC_BKS

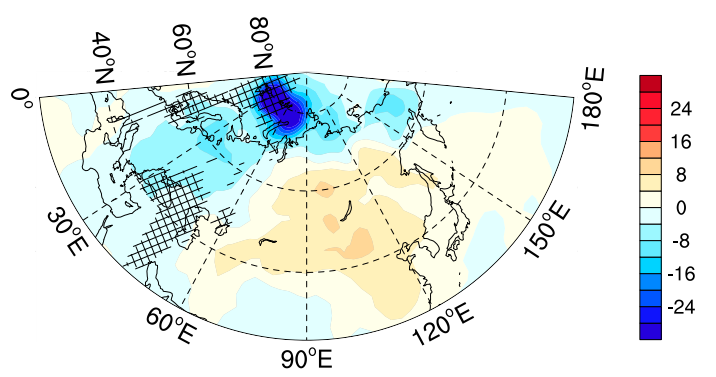

(c) Nov, SLP Reg. on SIC_BKS

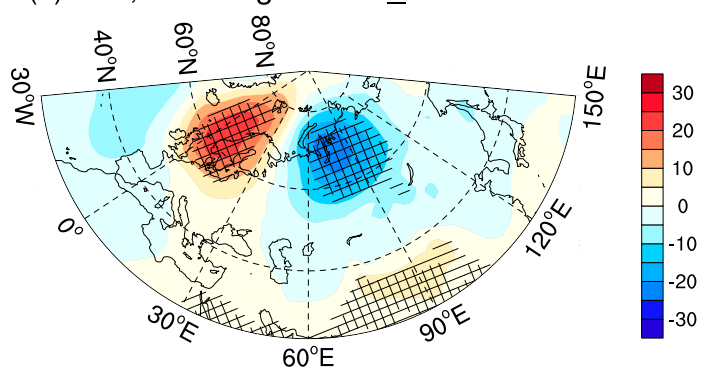

(d) Nov, WAF\&H500 Reg. on SIC_BKS

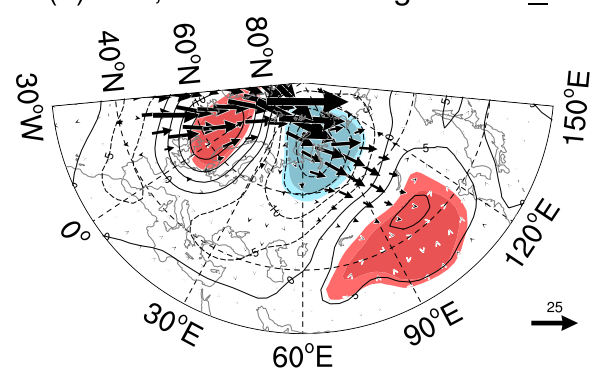

(e) WAF Reg. on SIC_BKS
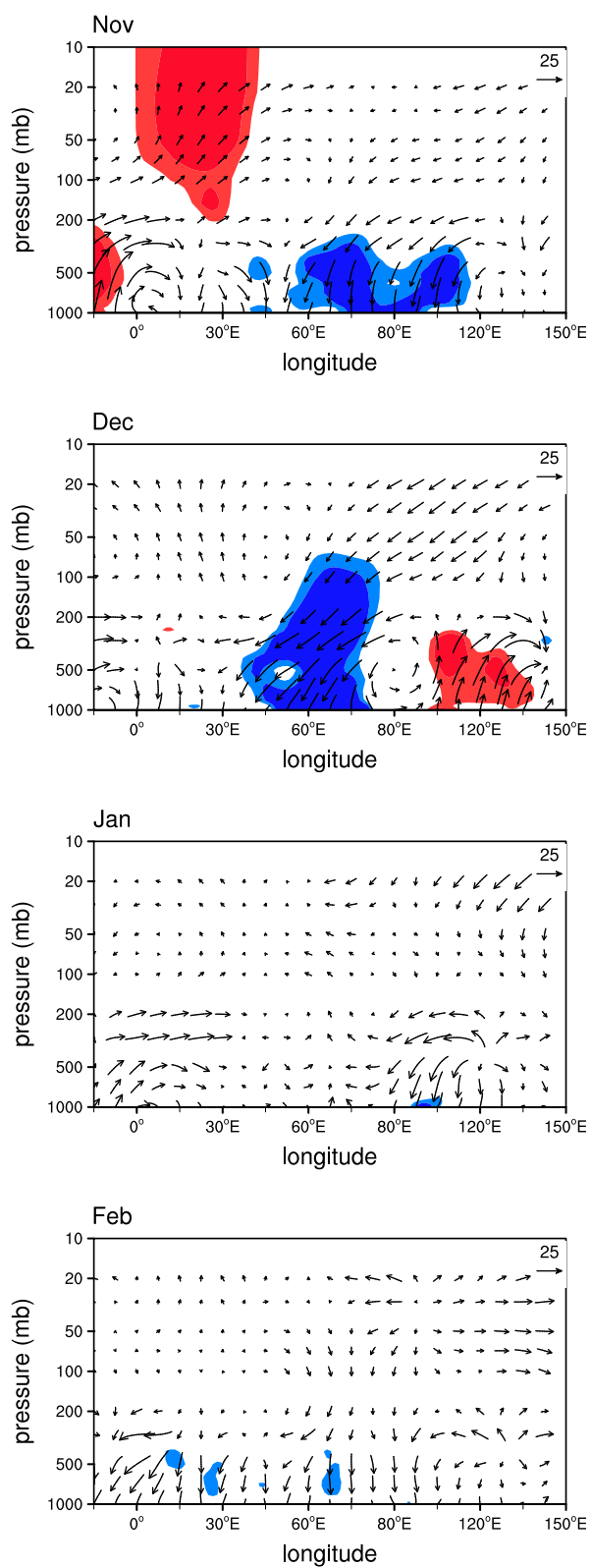

FIG. 10. Anomalous November (a) surface turbulent heat flux ( $\mathrm{W} \mathrm{m}^{-2}$; positive values denote upward heat flux), (b) surface air temperature $\left({ }^{\circ} \mathrm{C}\right)$, (c) sea level pressure (hPa), (d) 500-hPa geopotential height (contours; interval = $2 \mathrm{~m}$ ) and horizontal Takaya and Nakamura's (2001) wave activity flux (arrows; $\mathrm{m}^{2} \mathrm{~s}^{-2}$ ), and (e) zonal and vertical Plumb's (1985) wave activity flux at $60^{\circ} \mathrm{N}$ (arrows; $\mathrm{m}^{2} \mathrm{~s}^{-2}$ ) from November to February regressed onto November SIC index over Barents-Kara Sea during 1979-2015. Statistically significant values of vertical wave activity flux at the $95 \%(90 \%)$ confidence level (Student's $t$ test) are crosshatched (hatched) in (a)-(c) and have dark (light) shading in (d) and (e).

SIC_BKS distinctly affects NECTA in January-February. The above analyses indicate that heavy SIC_BKS in November impacts January-February NECTA through stratosphere-troposphere interaction, whereas light
SIC_DSBB in November mainly affects NECTA in December via the local SST over the North Atlantic. To clarify why this is the case, we carry out further investigations on the interannual variability and month-to-month 
(a) Standardized SIC_DM

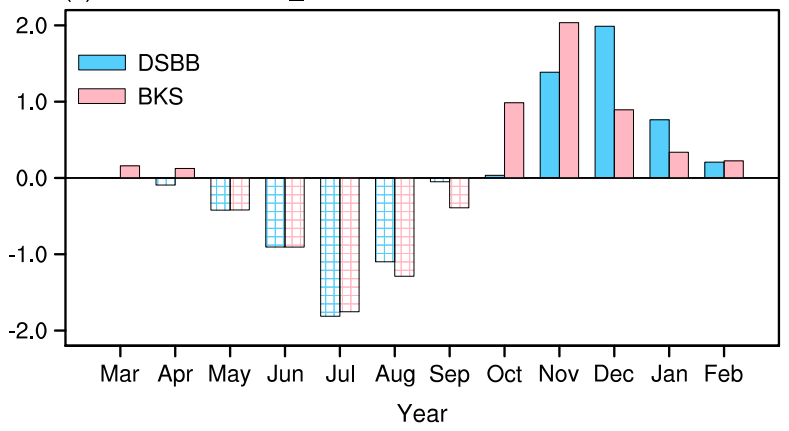

(b) Standard deviation of SIC

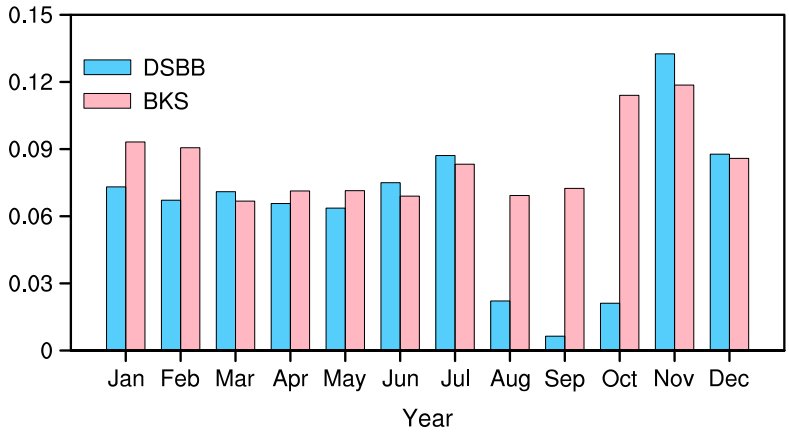

FIG. 11. The (a) standardized DM and (b) standard deviation of SIC (\%) for each month during 1979-2015.

increment of the SIC over the Davis Strait-Baffin Bay and the Barents-Kara Sea, as well as the related air-sea interaction.

By calculating the standard deviations of the SIC over the Davis Strait-Baffin Bay and the Barents-Kara Sea in each month during 1979-2016 (Fig. 11b), we find that the interannual variabilities of both SIC_DSBB and SIC_BKS reach a peak in November, and the values are comparable. However, the variation of SIC_DM over the Davis StraitBaffin Bay is smaller than that of the Barents-Kara Sea are in November (Fig. 11a). That means although sea ice cover features considerable variability over the Davis StraitBaffin Bay and the Barents-Kara Sea in November, larger DM of SIC_BKS could force greater response of general atmospheric or oceanic circulations compared with SIC DSBB. And SIC_DSBB anomalies may not be strong enough to have significant influences on the upward component of wave trains to affect the circulation systems in the Arctic stratosphere (Fig. 8a).

Screen (2017) documented that the Barents-Kara Seas are the only location where sea ice loss induces a significant stratospheric polar cap height response and emphasized the effect of linear interference related to anomalous ice cover. Figure 10 of their paper suggests that the forced response corresponding to negative SIC_BKS anomalies interferes constructively with the climatological wave, enhancing vertical wave activity propagation. But in the case of sea ice loss in the Archipelago-Baffin Bay, the tropospheric and stratospheric responses appear decoupled. Honda et al. (1999) illustrated that the atmospheric response to Arctic sea ice anomalies can be regarded as a stationary Rossby wave train generated thermally by anomalous turbulent heat fluxes. The regressed fields of turbulent heat flux from November to February against SIC_DSBB (left-hand column) and SIC BKS (right-hand column) index values are shown in Fig. 12. The turbulent heat flux corresponding to lighter than normal SIC_DSBB shows positive (around $30^{\circ}$ and $75^{\circ} \mathrm{N}$ ) and negative (around $60^{\circ} \mathrm{N}$ ) centers over the mid-tohigh latitudes of the North Atlantic in November, and this tripole pattern becomes distinct in December (Figs. 12a,b). The anomalous regressions of turbulent heat flux on SIC BKS index values characterize a local cooling source and a heating source to the south persisting to December over the Barents-Kara Sea (Figs. 12e,f). The anomalous heat flux corresponding to SIC_BKS is much stronger than that of SIC_DSBB in November.

To quantitatively describe the effect of November SIC over two domains on Rossby wave activities, an anomalous Rossby wave source (RWS) and divergent wind component at $1000 \mathrm{hPa}$ in November and December are regressed with indices of SIC-DSBB-DM (left column of Fig. 13) and SIC-BKS-DM (right column of Fig. 13) in November, respectively. RWS anomalies induced by November SIC-DSBB-DM characterize a negative center around $60^{\circ} \mathrm{N}$ over North Atlantic (Figs. 13a,b), which is much smaller than the local RWS center induced by larger DM of SIC-BKS (Figs. 13c,d) in November. With a more distinct anomalies of westerly winds extending from 1000 to $200 \mathrm{hPa}$, and vertically relative vorticity of wind related to heavier SIC_BKS in November (not shown), the suppressed stationary Rossby wave trains caused by heavier than normal SIC over the Barents-Kara Sea in November can easily affect the polar vortex in the Arctic stratosphere. In contrast with SIC_BKS, a small DM of November SIC_ DSBB anomalies could not excite great impacts on atmospheric circulations and could not persist to January. The weaker RWS induced by anomalous SIC_DSBB mainly propagates eastward to eastern Asia in November and December (Figs. 8e,f). The tripole heating pattern becomes weaker in the ensuing January and disappears in February (Figs. 12c,d), as do the corresponding general circulation anomalies (Figs. 5 and $8 \mathrm{~g}, \mathrm{~h})$. These features illustrate that the horizontal wave trains caused by November SIC_DSBB anomalies have significant effects on NECTA only in December.

The reasons why SIC_DSBB and SIC_BKS affect NECTA in December and January-February, respectively, can be explained as follows: 1) despite SIC_DSBB 
(a) Nov, THF Reg. on SIC DSBB

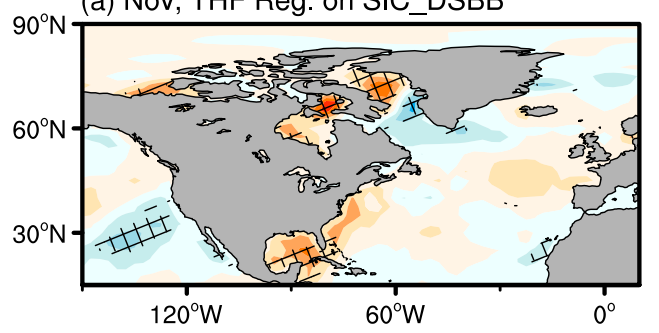

(b) Dec, THF Reg. on SIC_DSBB

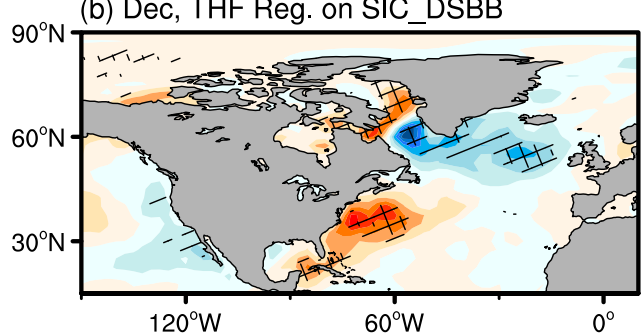

(c) Jan, THF Reg. on SIC_DSBB

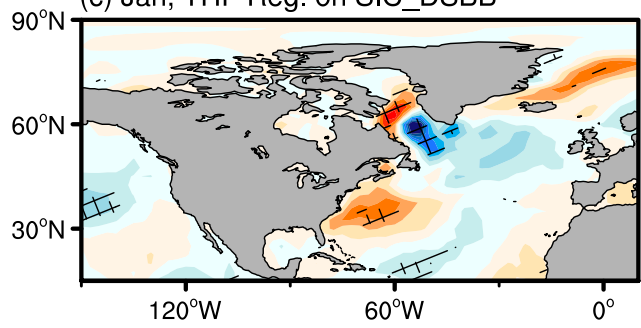

(d) Feb, THF Reg. on SIC DSBB

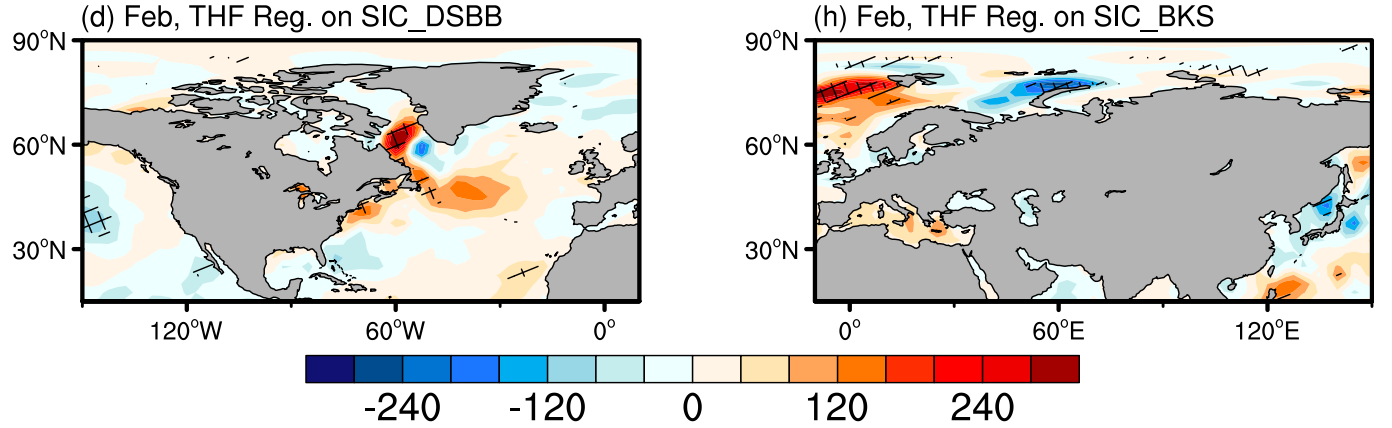

FIG. 12. Linear regression of (a),(e) November, (b),(f) December, (c),(g) January, and (d),(h) February surface turbulent heat flux ( $\mathrm{W} \mathrm{m}^{-2}$; positive values denote upward heat flux) anomalies onto SIC index over (left) Davis Strait-Baffin Bay $(\times-1.0)$ and (right) the Barents-Kara Sea. Statistically significant values at the $95 \%(90 \%)$ confidence level (Student's $t$ test) are crosshatched (hatched).
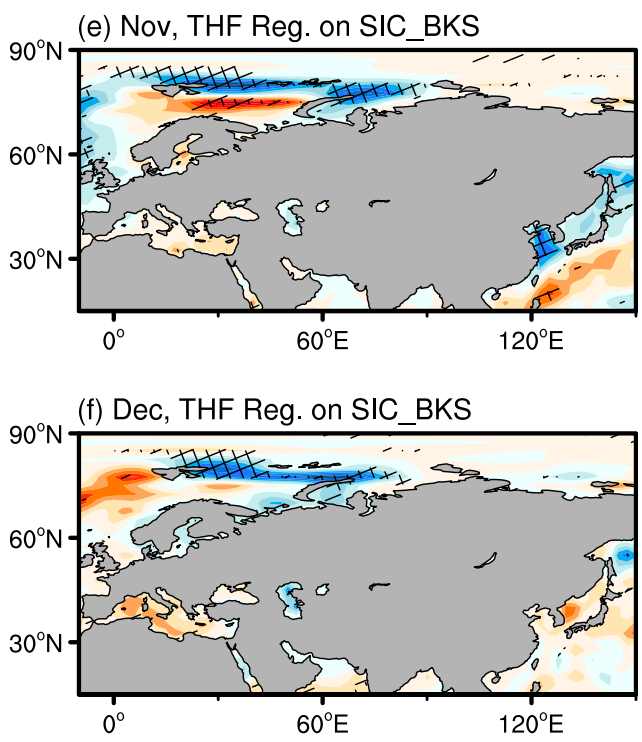

(g) Jan, THF Reg. on SIC_BKS

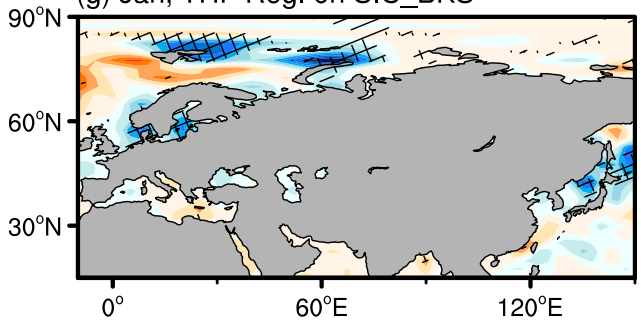

(h) Feb, THF Reg. on SIC_BKS and SIC_BKS having comparable interannual variations, the DM between October and November of SIC_DSBB is much smaller than that of SIC_BKS, which means the response of atmospheric and oceanic circulations to anomalous SIC_DSBB is weaker compared with SIC_ BKS; plus, 2) the air-sea interaction contributed by anomalous SIC_DSBB is weaker than that of SIC_BKS in November; meaning that 3) lighter than normal $\mathrm{SIC}_{-}$ DSBB in November mainly excites eastward-propagating
Rossby waves toward eastern China in November and December. Although slight vertical fluxes appear in December, the tropospheric and stratospheric responses appear decoupled through the wintertime.

\section{Conclusions and discussion}

In this study, we investigate the month-to-month variability of winter temperature anomalies over Northeast 

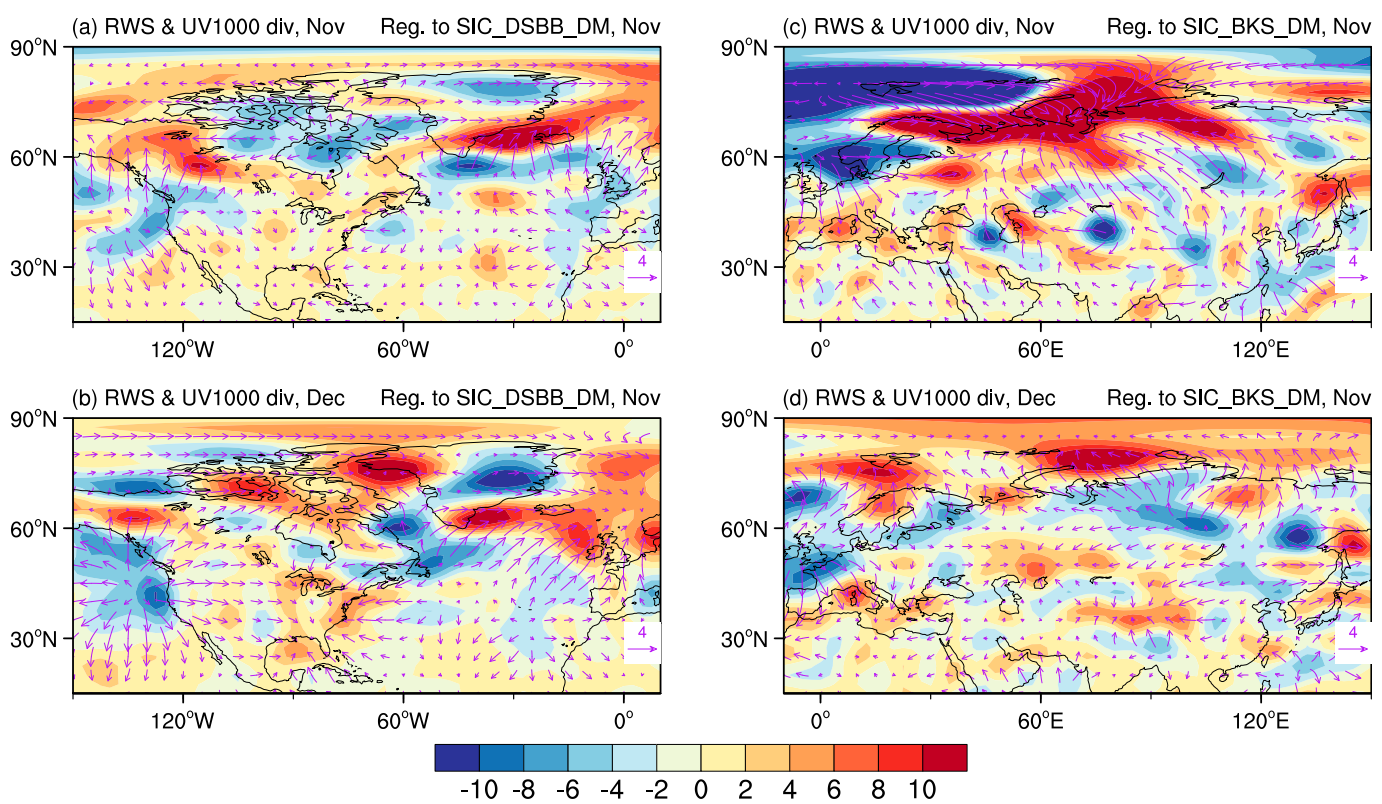

FIG. 13. Anomalous Rossby wave resource (shading; $10^{-11} \mathrm{~s}^{-2}$ ) and divergent wind component (arrows; $\mathrm{m}^{2} \mathrm{~s}^{-2}$ ) in November and December regressed with the November (a),(b) SIC-DSBB-DM index and (b),(d) SIC-BKS-DM index during 1979-2015.

China, especially the out-of-phase change between December and January-February (NECTA -++ NECTA $_{+--}$ events; colder than normal in December and warmer than normal in January-February, and vice versa), which accounts for the largest proportion of the number of years during recent decades. When a NECTA $-+{ }_{-+}$NECTA $_{+--}$ event happens, the phases of atmospheric circulation anomalies convert between December and JanuaryFebruary. Preliminary research indicates that the SIC over the Davis Strait-Baffin Bay $\left(62^{\circ}-75^{\circ} \mathrm{N}, 58^{\circ}-65^{\circ} \mathrm{W}\right)$ and the Barents-Kara Sea $\left(75^{\circ}-83^{\circ} \mathrm{N}, 0^{\circ}-80^{\circ} \mathrm{E}\right)$ in the preceding November may partly explain this subseasonal reversal phenomenon: SIC_DSBB mainly affects NECTA in December, whereas SIC_BKS has a significant influence on NECTA in January-February. Analyses based on SIC indices are conducted to elucidate the physical mechanisms by which anomalous SIC signals over those two domains propagate to Northeast China to impose considerable influence on winter temperatures there. The results show that the SST in the North Atlantic plays a key role in the process by which November SIC_DSBB affects December temperature over Northeast China. The negative phase of the SST tripole pattern in the North Atlantic linked to lighter than normal SIC_DSBB can contribute to a negative phase of NAO-like geopotential anomalies via the eddy-feedback mechanism, ultimately favoring cold conditions over Northeast China (Fig. 14).

However, SIC_BKS affects temperature over Northeast China mainly through stratosphere-troposphere interactions. As summarized schematically in Fig. 15, tropospheric wave trains from Barents-Kara Sea to Eurasia are generated thermally through turbulent heat flux as a result of anomalously high SIC_BKS in November, causing geopotential height anomalies over Eurasia. The anomaly pattern tends to suppress vertically propagating planetary-scale wave by destructively interfering with the climatological wave, which likely strengthens the stratospheric polar vortex and excites a

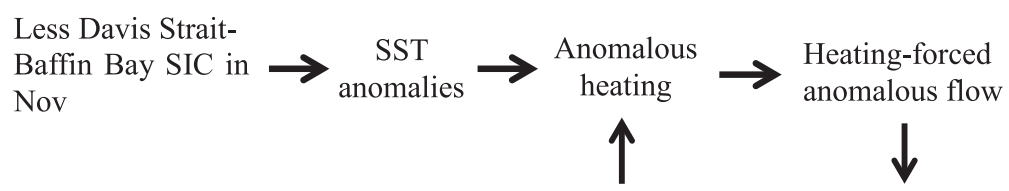

Anomalous temperature
over NEC in Dec $\begin{aligned} & \text { Eddy-forced NAO-like } \\ & \text { anomalous flow }\end{aligned} \begin{aligned} & \text { Dipole anomalous eddy } \\ & \text { vorticity forcing }\end{aligned}$

FIG. 14. Schematic illustrations of how the SIC over the Davis Strait-Baffin Bay in November impacts the atmospheric circulation and temperature over Northeast China in December. 


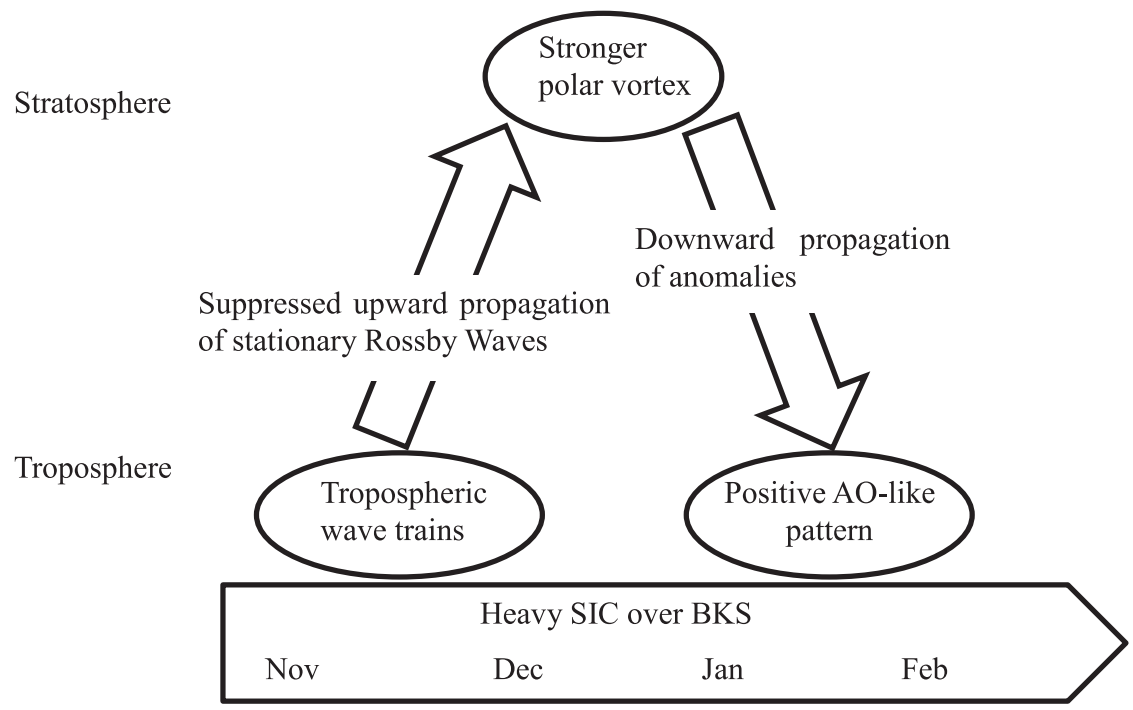

FIG. 15. Schematic illustrations of how the SIC over the Barents-Kara Sea in November impacts the atmospheric circulation and temperature over Northeast China during wintertime.

positive phase of an AO-like pattern in the stratosphere. Then, these stratospheric anomalies propagate downward leading to the AO-like pattern in the troposphere in January-February, favoring warm conditions in Northeast China.

But why does the sea ice over Davis Strait-Baffin Bay and the Barents-Kara Sea have different influences on NECTA? To address this, we further investigate the interannual variability and month-to-month increment of the SIC over those two domains. The results indicate that, despite the comparable interannual variability of SIC_DSBB and SIC_BKS, the month-to-month increment of SIC_DSBB is much smaller than that of SIC BKS in November (Fig. 11). The anomalous turbulent heat fluxes induced by the anomalous SIC over the Davis Strait-Baffin Bay and the Barents-Kara Sea are also taken into account. The strength of anomalous cooling and heating centers related to lighter than normal SIC_DSBB is much weaker than that of SIC_BKS in November (Figs. 12a,e), as well as the Rossby wave source (Figs. 13a,c). The regressed westerly anomalies and vertically relative vorticity of wind also characterize unfavorable conditions for troposphere-stratosphere interaction (not shown in this paper). Thus, the stationary Rossby wave trains related to anomalous SIC_ DSBB mostly spread to East Asia in November and December.

The present paper only takes into account the linear impact of November Arctic sea ice on NECTA N $_{-++} /$ NECTA $_{+--}$events. The associations between sea ice anomalies and atmospheric variabilities are complicated and nonlinear. Thus numerical experiments with the prescribed sea ice anomalies in the atmospheric model are needed. In addition, there will likely be other factors that contribute to the $\mathrm{NECTA}_{-++} / \mathrm{NECTA}_{+--}$phenomenon, such as the snow cover over Eurasia, the SST of the tropical oceans, and so on. SIC_DSBB in December can also affect NECTA in December. Moreover, different types of month-to-month variability of winter temperature over Northeast China may be related to different factors in different regions. We intend to address these open questions in future studies.

Acknowledgments. We thank the editor and reviewers for their helpful comments, which certainly resulted in an improved paper. This research was supported by the National Natural Science Foundation of China (Grants 41730964, 41575079, 41421004) and the National Key Research and Development Program of China (2018YFA0605901).

\section{REFERENCES}

Baldwin, M. P., and T. J. Dunkerton, 2001: Stratospheric harbingers of anomalous weather regimes. Science, 294, 581-584, https://doi.org/10.1126/science.1063315.

Ballinger, T. J., E. Hanna, R. J. Hall, J. Miller, M. H. Ribergaard, and J. L. Høyer, 2018: Greenland coastal air temperatures linked to Baffin Bay and Greenland Sea ice conditions during autumn through regional blocking patterns. Climate Dyn., $\mathbf{5 0}$, 83-100, https://doi.org/10.1007/s00382-017-3583-3.

Chang, C.-P., and M.-M. Lu, 2012: Intraseasonal predictability of Siberian high and East Asian winter monsoon and its interdecadal variability. J. Climate, 25, 1773-1778, https://doi.org/ 10.1175/JCLI-D-11-00500.1.

Chen, W., K. Wei, L. Wang, and Q. Zhou, 2013: Climate variability and mechanisms of the East Asian winter monsoon and the impact from the stratosphere (in Chinese). Chin. J. Atmos. Sci., 37, 425-438. 
Chen, X., and D. Luo, 2017: Arctic sea ice decline and continental cold anomalies: Upstream and downstream effects of Greenland blocking. Geophys. Res. Lett., 44, 3411-3419, https:// doi.org/10.1002/2016GL072387.

Chen, Z., R. Wu, and W. Chen, 2014: Impacts of autumn Arctic sea ice concentration changes on the East Asian winter monsoon variability. J. Climate, 27, 5433-5450, https://doi.org/10.1175/ JCLI-D-13-00731.1.

Dai, H., K. Fan, and B. Tian, 2018: A hybrid downscaling model for winter temperature over northeast China. Int. J. Climatol., 38, e349-e363, https://doi.org/10.1002/joc.5376.

Dickinson, R. E., 1968: Planetary Rossby waves propagating vertically through weak westerly wind wave guides. J. Atmos. Sci., 25, 984-1002, https://doi.org/10.1175/1520-0469(1968)025<0984: PRWPVT $>2.0 . \mathrm{CO} ; 2$.

Ding, Y., and T. N. Krishnamurti, 1987: Heat budget of the Siberian high and the winter monsoon. Mon. Wea. Rev., 115, 24282449, https://doi.org/10.1175/1520-0493(1987)115<2428: HBOTSH $>2.0$. CO;2.

— , and Coauthors, 2014: Interdecadal variability of the East Asian winter monsoon and its possible links to global climate change. J. Meteor. Res., 28, 693-713, https://doi.org/10.1007/ s13351-014-4046-y.

Eliassen, A., and E. Palm, 1961: On the transfer of energy in stationary mountain waves. Geofys. Publ., 22, 1-23.

Fan, K., H. Wang, and Y.-J. Choi, 2008: A physically-based statistical forecast model for the middle-lower reaches of the Yangtze River Valley summer rainfall. Chin. Sci. Bull., 53, 602-609, https://doi.org/10.1007/s11434-008-0083-1.

_ - Z. Xie, H. Wang, Z. Xu, and J. Liu, 2018: Frequency of spring dust weather in North China linked to sea ice variability in the Barents Sea. Climate Dyn., 51, 4439-4450, https://doi.org/ 10.1007/S00382-016-3515-7.

Gao, Y., and Coauthors, 2015: Arctic sea ice and Eurasian climate: A review. Adv. Atmos. $S c i ., 32,92-114$, https://doi.org/10.1007/ s00376-014-0009-6.

García-Serrano, J., C. Frankignoul, G. Gastineau, and A. de la Cámara, 2015: On the predictability of the winter Euro-Atlantic climate: Lagged influence of autumn Arctic sea ice. J. Climate, 28, 51955216, https://doi.org/10.1175/JCLI-D-14-00472.1.

_ - and Coauthors, 2017: Multi-model assessment of linkages between eastern Arctic sea-ice variability and the Euro-Atlantic atmospheric circulation in current climate. Climate Dyn., 49, 2407-2429, https://doi.org/10.1007/s00382-016-3454-3.

Geng, X., W. Zhang, M. F. Stuecker, and F.-F. Jin, 2017: Strong sub-seasonal wintertime cooling over East Asia and northern Europe associated with super El Niño events. Sci. Rep., 7, 3770, https://doi.org/10.1038/s41598-017-03977-2.

He, S., Y. Gao, F. Li, H. Wang, and Y. He, 2017: Impact of Arctic Oscillation on the East Asian climate: A review. Earth Sci. Rev., 164, 48-62, https://doi.org/10.1016/j.earscirev.2016.10.014.

Honda, M., K. Yamazaki, H. Nakamura, and K. Takeuchi, 1999: Dynamic and thermodynamic characteristics of atmospheric response to anomalous sea-ice extent in the Sea of Okhotsk. J. Climate, 12, 3347-3358, https://doi.org/10.1175/ 1520-0442(1999)012<3347:DATCOA > 2.0.CO;2.

_ J. Inoue, and S. Yamane, 2009: Influence of low Arctic sea-ice minima on anomalously cold Eurasian winters. Geophys. Res. Lett., 36, L08707, https://doi.org/10.1029/2008GL037079.

$\mathrm{Hu}, \mathrm{C}$., S. Yang, and Q. Wu, 2015: An optimal index for measuring the effect of East Asian winter monsoon on China winter temperature. Climate Dyn., 45, 2571-2589, https://doi.org/ 10.1007/s00382-015-2493-5.
Inoue, J., M. E. Hori, and K. Takaya, 2012: The role of Barents Sea ice in the wintertime cyclone track and emergence of a warmArctic cold-Siberian anomaly. J. Climate, 25, 2561-2568, https://doi.org/10.1175/JCLI-D-11-00449.1.

Kalnay, E., and Coauthors, 1996: The NCEP/NCAR 40-Year Reanalysis Project. Bull. Amer. Meteor. Soc., 77, 437-471, https:// doi.org/10.1175/1520-0477(1996)077<0437:TNYRP>2.0.CO;2.

Kim, B. M., S.-W. Son, S.-K. Min, J.-H. Jeong, S.-J. Kim, X. Zhang, T. Shim, and J.-H. Yoon, 2014: Weakening of the stratospheric polar vortex by Arctic sea-ice loss. Nat. Commun., 5, 4646, https://doi.org/10.1038/ncomms5646.

King, M. P., M. Hell, and N. Keenlyside, 2016: Investigation of the atmospheric mechanisms related to the autumn sea ice and winter circulation link in the Northern Hemisphere. Climate Dyn., 46, 1185-1195, https://doi.org/10.1007/s00382-015-2639-5.

Kuroda, Y., and K. Kodera, 1999: Role of planetary waves in the stratosphere-troposphere coupled variability in the Northern Hemisphere winter. Geophys. Res. Lett., 26, 2375-2378, https://doi.org/10.1029/1999GL900507.

Li, Y., and S. Yang, 2010: A dynamical index for the East Asian winter monsoon. J. Climate, 23, 4255-4262, https://doi.org/ 10.1175/2010JCLI3375.1.

Liu, J., J. A. Curry, H. Wang, M. Song, and R. M. Horton, 2012: Impact of declining Arctic sea ice on winter snowfall. Proc. Natl. Acad. Sci. USA, 109, 4074-4079, https://doi.org/10.1073/ pnas.1114910109.

Liu, S., and Coauthors, 2010: Time-frequency characteristics of regional climate over northeast China and their relationships with atmospheric circulation patterns. J. Climate, 23, 49564972, https://doi.org/10.1175/2010JCLI3554.1.

Mysak, L. A., R. G. Ingram, J. Wang, and A. van der Baaren, 1996: The anomalous sea-ice extent in Hudson Bay, Baffin Bay and the Labrador Sea during three simultaneous NAO and ENSO episodes. Atmos.-Ocean, 34, 313-343, https://doi.org/10.1080/ 07055900.1996 .9649567$.

Nakamura, T., K. Yamazaki, K. Iwamoto, M. Honda, Y. Miyoshi, Y. Ogawa, and J. Ukita, 2015: A negative phase shift of the winter $\mathrm{AO} / \mathrm{NAO}$ due to the recent Arctic sea-ice reduction in late autumn. J. Geophys. Res. Atmos., 120, 3209-3227, https:// doi.org/10.1002/2014JD022848.

$-,-,-\longrightarrow,-,-$, Y. Tomikawa, and J. Ukita, 2016: The stratospheric pathway for Arctic impacts on midlatitude climate. Geophys. Res. Lett., 43, 3494-3501, https:// doi.org/10.1002/2016GL068330.

Outten, S. D., and I. Esau, 2012: A link between Arctic sea ice and recent cooling trends over Eurasia. Climatic Change, 110, 1069-1075, https://doi.org/10.1007/s10584-011-0334-z.

Park, D.-S. R., S. Lee, and S. B. Feldstein, 2015: Attribution of the recent winter sea ice decline over the Atlantic sector of the Arctic Ocean. J. Climate, 28, 4027-4033, https://doi.org/ 10.1175/JCLI-D-15-0042.1.

Peng, S., and J. S. Whitaker, 1999: Mechanisms determining the atmospheric response to midlatitude SST anomalies. J. Climate, 12, 1393-1408, https://doi.org/10.1175/1520-0442(1999)012<1393: MDTART $>2.0 . \mathrm{CO} ; 2$.

- W. A. Robinson, and S. Li, 2003: Mechanisms for the NAO responses to the North Atlantic SST tripole. J. Climate, 16, 1987-2004, https://doi.org/10.1175/1520-0442(2003)016<1987: MFTNRT $>2.0 . \mathrm{CO} ; 2$.

Petoukhov, V., and V. A. Semenov, 2010: A link between reduced Barents-Kara sea ice and cold winter extremes over northern continents. J. Geophys. Res., 115, D21111, https://doi.org/ 10.1029/2009JD013568. 
Plumb, R. A., 1985: On the three-dimensional propagation of stationary waves. J. Atmos. Sci., 42, 217-229, https://doi.org/ 10.1175/1520-0469(1985)042<0217:OTTDPO > 2.0.CO;2.

Rayner, N. A., and Coauthors, 2003: Global analyses of sea surface temperature, sea ice, and night marine air temperature since the late nineteenth century. J. Geophys. Res., 108, 4407, https://doi.org/10.1029/2002JD002670.

Sato, K., J. Inoue, and M. Watanabe, 2014: Influence of the Gulf Stream on the Barents Sea ice retreat and Eurasian coldness during early winter. Environ. Res. Lett., 9, 084009, https:// doi.org/10.1088/1748-9326/9/8/084009.

Screen, J. A., 2017: Simulated atmospheric response to regional and pan-Arctic sea ice loss. J. Climate, 30, 3945-3962, https:// doi.org/10.1175/JCLI-D-16-0197.1.

Semenov, V. A., and M. Latif, 2015: Nonlinear winter atmospheric circulation response to Arctic sea ice concentration anomalies for different periods during 1966-2012. Environ. Res. Lett., 10, 054020, https://doi.org/10.1088/1748-9326/10/5/054020.

Si, D., Q. Li, Y. Liu, Z. Wang, Y. Yuan, and D. Wang, 2014: Possible causes for the anomalous weak East Asian winter monsoon in 2013/2014. Meteor. Mon., 40, 891-897.

, L. Ma, P. Wang, Y. Wang, Y. Nie, and L. Sun, 2016: Anomalous activity of Arctic Oscillation in winter 2015/2016 and its impact on temperature in China. Meteor. Mon., 42, 892-897.

Stern, H. L., and M. P. Heide-Jørgensen, 2016: Trends and variability of sea ice in Baffin Bay and Davis Strait, 1953-2001. Polar Res., 22, 11-18, https://doi.org/10.3402/polar.v22i1.6438.

Sun, C., S. Yang, W. Li, R. Zhang, and R. Wu, 2016: Interannual variations of the dominant modes of East Asian winter monsoon and possible links to Arctic sea ice. Climate Dyn., 47, 481-496, https://doi.org/10.1007/s00382-015-2851-3.

Sun, L., C. Deser, and R. A. Tomas, 2015: Mechanisms of stratospheric and tropospheric circulation response to projected Arctic sea ice loss. J. Climate, 28, 7824-7845, https://doi.org/ 10.1175/JCLI-D-15-0169.1.

Takaya, K., and H. Nakamura, 2001: A formulation of a phaseindependent wave-activity flux for stationary and migratory quasigeostrophic eddies on a zonally varying basic flow. J. Atmos. Sci., 58, 608-627, https://doi.org/10.1175/15200469(2001)058<0608:AFOAPI >2.0.CO;2.

Wang, D., Z. Bing, S. Chenghu, Y. Yuan, L. Yanju, and W. Pengling, 2013: Features and possible causes for East Asian winter monsoon in 2012/2013. Meteor. Mon., 39, 930-937.

— T. Cui, D. Si, X. Shao, Q. Li, and C. Sun, 2015: Features and possible causes for East Asian winter monsoon in 2014/2015. Meteor. Mon., 41, 907-914.

Wang, H., and S. He, 2012: Weakening relationship between East Asian winter monsoon and ENSO after mid-1970s. Chin. Sci. Bull., 57, 3535-3540, https://doi.org/10.1007/s11434-012-5285-x.
Wang, J., and Y. Guo, 2004: Possible impacts of Barents Sea ice on the Eurasian atmospheric circulation and the rainfall of East China in the beginning of summer. Adv. Atmos. Sci., 21, 662674, https://doi.org/10.1007/BF02915733.

_ L. L. A. Mysak, and R. G. Ingram, 1994: Interannual variability of sea-ice cover in Hudson Bay, Baffin Bay and the Labrador Sea. Atmos.-Ocean, 32, 421-447, https://doi.org/10.1080/ 07055900.1994 .9649505$.

Wang, L., and W. Chen, 2010: Downward Arctic Oscillation signal associated with moderate weak stratospheric polar vortex and the cold December 2009. Geophys. Res. Lett., 37, L09707, https://doi.org/10.1029/2010GL042659.

Wu, B., and J. Wang, 2002: Winter Arctic Oscillation, Siberian high and East Asian winter monsoon. Geophys. Res. Lett., 29, 1897 https://doi.org/10.1029/2002GL015373.

-, R. Huang, and D. Gao, 1999: Impact of variation of sea-ice extent in the Kara Sea and the Barents Seas in winter on the winter monsoon over East Asia (in Chinese). Chin. J. Atmos. Sci., 23, 267-275.

_- J. Su, and R. Zhang, 2011: Effects of autumn-winter Arctic sea ice on winter Siberian high. Chin. Sci. Bull., 56, 3220-3228, https://doi.org/10.1007/s11434-011-4696-4.

_ , R. Zhang, R. D'Arrigo, and J. Su, 2013: On the relationship between winter sea ice and summer atmospheric circulation over Eurasia. J. Climate, 26, 5523-5536, https://doi.org/10.1175/ JCLI-D-12-00524.1.

Wu, Q., and X. Zhang, 2010: Observed forcing-feedback processes between Northern Hemisphere atmospheric circulation and Arctic sea ice coverage. J. Geophys. Res., 115, D14119, https:// doi.org/10.1029/2009JD013574.

Yang, L., and B. Wu, 2013: Interdecadal variations of the East Asian winter surface air temperature and possible causes. Chin. Sci. Bull., 58, 3969-3977, https://doi.org/10.1007/s11434013-5911-2.

Yang, S., K. Lau, and K. Kim, 2002: Variations of the East Asian jet stream and Asian-Pacific-American winter climate anomalies. J. Climate, 15, 306-325, https://doi.org/10.1175/15200442(2002)015<0306:VOTEAJ > 2.0.CO;2.

Zhang, D., and W. Song, 2018: Northern Hemisphere atmospheric circulation characteristics in 2017/2018 winter and its impact on weather and climate in China. Meteor. Mon., 44, 969-976.

Zhuang, Y., J. Zhang, and L. Wang, 2018: Variability of cold season surface air temperature over northeastern China and its linkage with large-scale atmospheric circulations. Theor. Appl. Climatol., 132, 1261-1273, https://doi.org/10.1007/s00704-0172166-x.

Zuo, J., H. Ren, B. Wu, and W. Li, 2016: Predictability of winter temperature in China from previous autumn Arctic sea ice. Climate Dyn., 47, 2331-2343, https://doi.org/10.1007/s00382 015-2966-6. 